Portland State University

PDXScholar

\title{
Intensive ESL Course Performance as a Predictor of Academic Success
}

\author{
Coleman South \\ Portland State University
}

Follow this and additional works at: https://pdxscholar.library.pdx.edu/open_access_etds

Part of the Bilingual, Multilingual, and Multicultural Education Commons Let us know how access to this document benefits you.

\section{Recommended Citation}

South, Coleman, "Intensive ESL Course Performance as a Predictor of Academic Success" (1992). Dissertations and Theses. Paper 4569.

https://doi.org/10.15760/etd.6453

This Thesis is brought to you for free and open access. It has been accepted for inclusion in Dissertations and Theses by an authorized administrator of PDXScholar. Please contact us if we can make this document more accessible: pdxscholar@pdx.edu. 
AN ABSTRACT OF THE DISSERTATION OF Coleman South for the Master of Arts in TESOL presented May 20, 1992.

Title: Intensive ESL Course Performance as a Predictor of Academic Success.

APPROVED BY THE MEMBERS OF THE DISSERTATION COMMITTEE:



Kimberley Brown, Chair
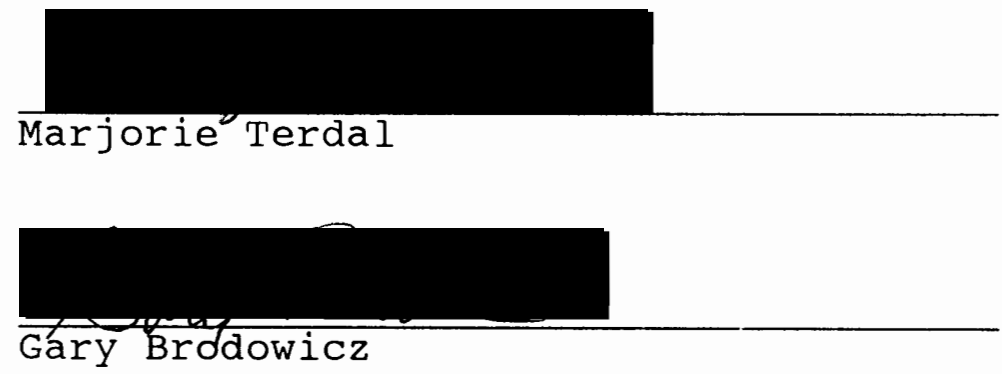

In order to determine the reliability of international students' English as a Second Language (ESL) class performance as a predictor of academic performance, a population of 169 international students at Portland state University (PSU) in Portland, Oregon were selected and statistical tests were performed on their GPAs and TOEFL scores.

Individual students' GPAs were computed for all ESL classes taken and for each component--grammar, reading, writing, and speaking/listening--as well as for the end of 
the first quarter, first year, and second year of academic study. Pearson Coefficient Correlations were then computed for the ESL and academic GPAs.

The students were also divided into subgroups based upon gender, nature of academic major (more-verbal or lessverbal), age, nationality (Asian or Middle-Eastern), number of ESL classes taken, amount of previous English-speaking college experience, prior education level, TOEFL score, and PSU entry date. Then mean GPAs were calculated for each of these which were compared by T-tests.

The results were mixed. While it was clear that ESL grades and academic grades correlated strongly for some variable groups, it was difficult to determine which variables had the strongest effect because of subgroup composition. For example, female students, students from Asia, and students whose majors fit the more-verbal category showed strong and statistically significant correlations for ESL-second year academic grades; but $90 \%$ of the women were from countries of Asia, and the proportion of both Asian and female students in the more-verbal majors was much higher than that of males or students from countries of the Middle East.

There were two patterns that stood out in the research results. One was that ESL students who had taken twelve or more ESL classes maintained consistent academic GPAs across time, while those who had taken fewer than twelve ESL 
classes and all students in the non-ESL group had GPAs that started higher than those of the first group but declined over the two year period--some of them enough to be statistically significant.

The second pattern was that groups with strong ESLacademic GPA correlations tended to do better in college that did those with weaker ESL-academic GPA relationships. TOEFL scores were correlated to both ESL and academic grades. In the first case, there were both moderately positive and statistically significant relationships. In the second case, the correlations were very low; and for non-ESL students, there was essentially no correlation. But comparing mean academic GPAs showed a significant difference between students who scored below 500 and those who scored 500 and above on the TOEFL. 
INTENSIVE ESL COURSE PERFORMANCE AS A PREDICTOR OF ACADEMIC SUCCESS

by

COLEMAN SOUTH

A thesis submitted in partial fulfillment of the requirement for the degree of

MASTER OF ARTS

in

TESOL

Portland State University

1992 
TO THE OFFICE OF GRADUATE STUDIES:

The members of the Committee approve the thesis of Coleman South presented May 20, 1992.

Kimberley Brown, Chair

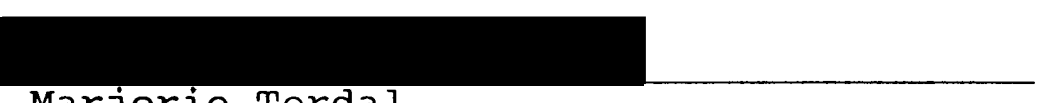
Marjorie Terdal

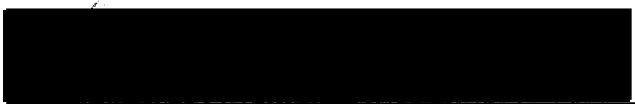

Gary Brddowicz

APPROVED :

$\mathrm{J} / \mathrm{gmes}$ Nattinger, Chair, Department of Applied Linguistics Vy

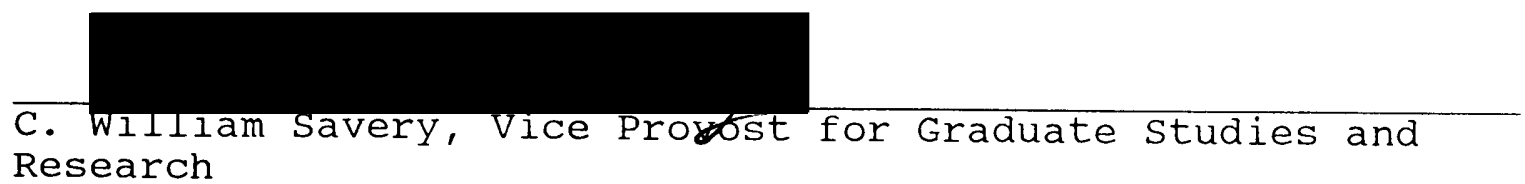


To Robin, who helped make it all possible 


\section{ACKNOWLEDGEMENTS}

My gratitude goes to Kim for her encouragement, advice, and tireless reading and rereading of my manuscript drafts; to Marge for her advice and assistance; to Joel for his help in setting up and processing my data; to Gary for his service on my committee and for agreeing to a defense date on a short notice; to Eric for his statistics advise; to Dale and Belen in the office of Institutional Research and Fran in the Registrar's office for their assistance in collecting my data; to Maureen in the Graduate office for her patient assistance in formatting the manuscript; to my fellow teachers and students for their ideas and information; to Robin for countless tasks both small and large; and to Gina for her encouragement and sympathetic ear. 
TABLE OF CONTENTS

PAGE

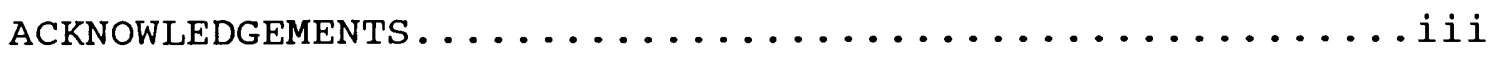

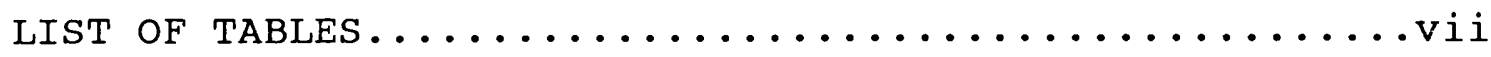

LIST OF FIGURES..........................

CHAPTER

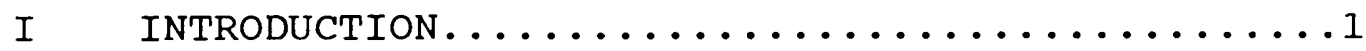

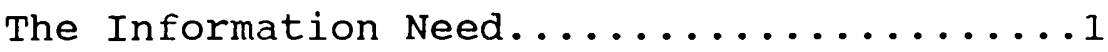

Description of the ESL Program at PSU.....2

Hypotheses........................

II LITERATURE REVIEW..................

Introduction....................

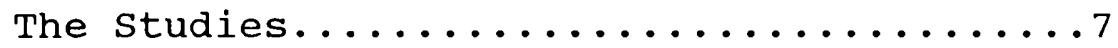

English Language Training

English Proficiency Tests

Previous Scholastic Performance

Combined and other Variables

Conclusions from the Literature Review....16

Measurement Problems

III METHOD AND PROCEDURES..................... 0

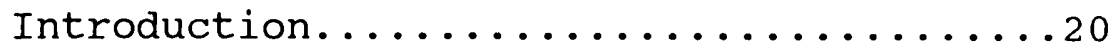

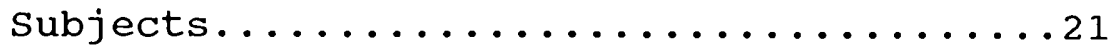

Selection

Highlights of Subgroup Composition

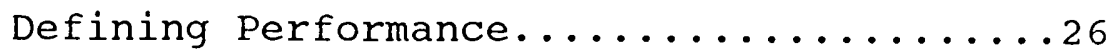




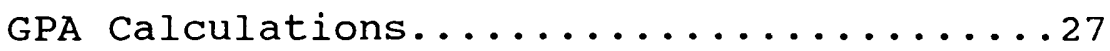

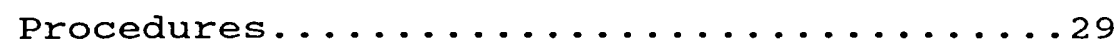

The Data

The Statistical Tests

IV RESULTS OF STATISTICAL TESTS................ 31

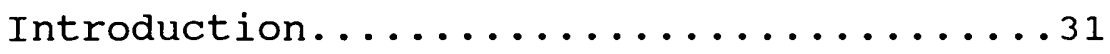

ESL and Academic GPA Relationships.......32

Pearson Correlation Coefficients

Mean GPA Differences between ESL

subgroups................49

ESL Grades

Academic Grades

Comparing GPAs of ESL and Non-ESL

students...................54

Full Groups

Gender

Nationality

TOEFL Score and GPA Relationships.......57

TOEFL Score-ESL Grade correlations

Correlating with Academic Grades

$\mathrm{V}$ DISCUSSION AND IMPLICATIONS............61

Predictive Validity of ESL Grades.......61

The Perceived Goals of ESL Instruction

Weaknesses in Predictive Value of ESL Grades

Mean Academic GPA Differences

Comparing ESL and Non-ESL Students......72

TOEFL Scores as Predictor..............73

TOEFL-ESL Grades

TOEFL-Academic Grades 
Summary and Suggestions for Further

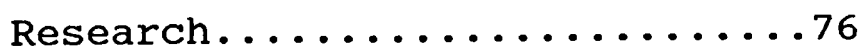

REFERENCES............................

APPENDICES

A MAIN GROUP COMPOSITION................. 85

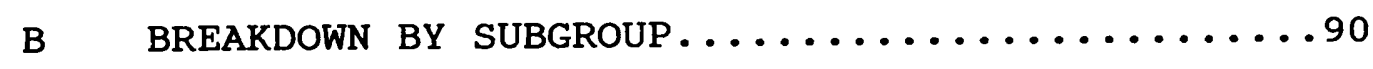

C GPA AND TOEFL SCORE DISTRIBUTIONS............93 


\section{LIST OF TABLES}

TABLE

PAGE

ESL-Academic GPA Correlations, all ESL

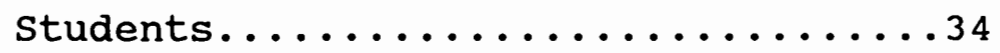

II ESL-Academic GPA Correlations, Male

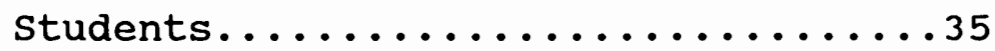

III ESL-Academic GPA Correlations, Female

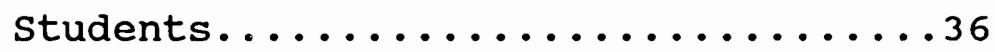

IV ESI-Academic GPA Correlations,

Less-Verbal Major students........39

V ESL-Academic GPA Correlations,

More-Verbal Major Students.........39

VI ESL-Academic GPA Correlations, students

24 Years \& older.................40

VII ESL-Academic GPA Correlations, students

under 24 Years...................41

VIII ESL-Academic GPA Correlations,

Middle-Eastern Students..........41

IX ESL-Academic GPA Correlations, Asian

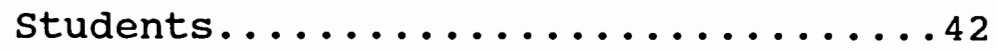

X ESL-Academic GPA Correlations, students

with Fewer Than 12 ESL Classes......43

XI ESL-Academic GPA Correlations, students

with 12 or More ESL Classes........43 
viii

XII ESL-Academic GPA Correlations, students

with No Previous English-Speaking

College Experience.............46

XIII ESL-Academic GPA Correlations, students

with Some Previous English-Speaking

College Experience.............47

XIV Mean Academic GPA Differences by

Gender, ESL students............51

XV Mean Academic GPA Differences by

Nationality, ESL students.........51

XVI Mean Academic GPA Differences by Prior

Education Level, ESL Students.......52

XVII Mean Academic GPA Differences by TOEFL

Score Grouping, ESL Students.......52

XVIII Mean Academic GPAs by Number of ESL Classes. 53

XIX Mean Academic GPA Differences between

ESL and Non-ESL Students.........54

XX Mean Academic GPA Differences between

ESL and Non-ESL Male students......55

XXI Mean Academic GPA Standard Deviations

for ESL and Non-ESL Students

from Middle East.................55

XXII Mean Academic GPA Differences between

ESL and Non-ESL Students from Asia...56

XXIII Academic GPA Drop of Non-ESL Students......57 
XXIV TOEFL Score-ESL GPA Correlations.........57

XXV TOEFL Score-Second year Academic

GPA Correlations..................59

XXVI ESL and Academic Subgroup Means by

Gender and Nationality............72 


\section{LIST OF FIGURES}

FIGURE

PAGE

1. Subject Grouping Hierarchy...............23

2. Male ESL Students' ESL-Second Academic

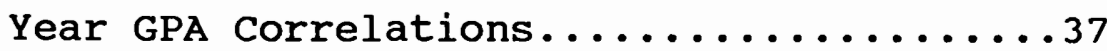

3. Female ESL Students' ESL-Second Academic

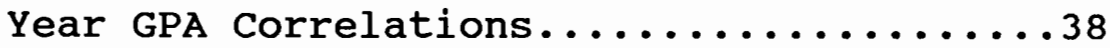

4. ESL-2nd Year Academic GPA Correlations: Students

Who Took Less Than 12 ESL Classes........44

5. ESL-2nd Year Academic GPA Correlations: Students

Who Took 12 or More ESL Classes........45

6. Correlation between TOEFL Scores and

ESL Grammar GPAs..................58

7. Correlation of TOEFL Scores to Second

Year Academic Grades for ESL Students.....59

8. Correlation of TOEFL Scores to Second

Year Academic Grades for Non-ESL Students.60 
CHAPTER I

INTRODUCTION

THE INFORMATION NEED

The importance of international students to higher education in the U.S. is growing annually, and Portland State University (PSU) is part of that trend. The number of students on F-1 (study) visas at PSU increased $9 \%$ between fall, 1989 and a year later--from 740 to 809 (PSU Office of Institutional Research and Planning).

What are the primary courses of study chosen by the international students? Until 1989, more than half of those students nationwide majored in some type of engineering; but during 1990, the percentage in engineering programs was surpassed by those in business studies: $19 \%$ and 20\%, respectively (Wilson, 1990). At PSU, the number of international students enrolled in engineering programs declined from 142 during the 1989-1990 school year to 140 the following year. During the same time, the number declaring business and management majors rose from 176 to 186--a total of nearly $23 \%$ of international enrollment. Assessing the academic preparation of students from diverse countries is difficult at best (Perry, 1989), so 
reliable predictors of their academic success are needed. Wardlow (1989) used a full population of 327 Moroccan students at the University of Minnesota and discovered that their English proficiency was more strongly related to their academic success than were their scholastic backgrounds, as evaluated by his university. Additionally, intensive English programs are growing, changing, and searching for ways to better help their students to become reasonably proficient in the language and to adapt culturally as well as academically.

Admissions offices, departments within universities, and the students themselves all need reliable predictors of academic success. Additionally, English as a second Language (ESL) program staff and administrators want to know if their programs are effective.

\section{DESCRIPTION OF THE ESL PROGRAM AT PSU}

Intensive English classes were first established at PSU in 1964, to assist students from Saudi Arabia in their English acquisition. The program has four levels (I-beginning, II-low intermediate, III-intermediate, and IV-advanced), each of which consists of four components: grammar, reading, writing, and speaking/listening. The reading and writing components occasionally have the same instructors, and students are strongly advised to take those courses together. Until 1989, there were also other 
classes offered: vocabulary, pronunciation, library, study skills, and cultural orientation. These functions are now included within the four main segments. The program includes other classes as well: a preparatory class for the Test of English as a Foreign Language (TOEFL) for advanced students; a new class to assist international graduate teaching assistants with their pronunciation, stress, intonation, and classroom teaching skills; and a new adjunct geography class.

「PSU requires undergraduate students from countries where English is not the primary language to achieve a minimum score of 525 on the TOEFL prior to beginning academic study. If they do not meet this guideline, they are tested (the Michigan [Michigan Test of English Language Proficiency], the CELT [Comprehensive English Language Test], and a holistically-scored in-house writing test) and placed in appropriate levels of ESL classes. An undergraduate who has attended and passed at least the highest level (Level 4 ) of ESL classes may be allowed to begin academic courses with a TOEFL score of 500 and the permission of the ESL program coordinator. Also, advanced students may be allowed to take some academic courses (again, based upon required approval) when they are in their final quarter of ESL. These courses are usually of the 'less-verbal' type--math, music, etc. 
The ESL program falls under the auspices of the Department of Applied Linguistics and relies heavily upon students from its Teaching English to Speakers of other Languages (TESOL) teacher training program for both tutors and Graduate Teaching Assistants (TAs). Full time teachers teach 12 hours per week, part time, 8-11 hours, and TAs, 5 hours. During the 1991-1992 academic year, there were three full-time and four part-time instructors as well as eight TAs. Several of the teachers and some TAs also teach English for Non-Native Residents (ENNR), a separate but similar intensive English program also administered by the Applied Linguistics Department.

\section{HYPOTHESES}

This study was undertaken to determine the predictive value of intensive English language program performance for undergraduate academic performance (the criterion variable-Brown, 1988) by: a) establishing the correlations of both overall and component ESL grade point averages (GPAS) with later academic GPAs for all ESL subjects and for those grouped by moderator variables (factors that might moderate the affect of predictive or criterion variables) and $b$ ) comparing the academic GPAs of students who have taken at least four ESL classes with those of students who have not. The following hypotheses were to be tested: 
1. F-1 visa students' ESL GPAs will correlate significantly and positively with their college GPAs at the end of the first year of academic study, but not at the end of the second year.

2. The correlations of overall ESL GPAs to academic GPAs and those of specific language skill (reading, writing, etc) GPAs to academic GPAs will be essentially the same.

3. ESL GPAS will correlate to academic GPAs more strongly for more-verbal majors than they will for less-verbal majors.

4. The correlations of ESL to academic GPAs among the moderator variable groups of gender, age, and nationality will be essentially the same.

5. There will be no statistically significant difference between the mean academic GPA of former ESL students and the mean academic GPA of other F-1 visa students who have taken no intensive English classes in the U.S. 
CHAPTER II

\section{LITERATURE REVIEW}

\section{INTRODUCTION}

The studies reviewed for this research correlated dozens of possible predictive variables with the criterion variable of academic performance for international students in the U.S. and found relationships that ranged from moderately negative to strongly positive (Dunn, 1990; Wardlow, 1989).

Some have used graduate students (Hwang \& Dizney, 1970; Covert \& Chansky, 1975), while others used undergraduates (Sugimoto, 1966; Harvey, 1979); some have used standardized test scores (Burgess \& Greis, 1970; Sharon, 1972), while others used non-cognitive factors (White \& Sedlacek, 1986; Boyer \& Sedlacek, 1988); and some have used pre- or postadmission English test or English class scores (Rosberg, 1983; Woodbridge, 1986), while others used prior academic performance--high school or undergraduate (Perry, 1989; Case \& Richardson, 1990).

The studies reported here are arranged by possible predictor or moderator variables (as defined by the authors), and within those categories, by the results. 
THE STUDIES

English Language Training

No Significant Results. One of the first studies to correlate ESL course performance to later college work was undertaken by Mason (1971). He compared the content-course performance and scores on a post-first semester English skills test of 15 ESL students and 9 non-ESL foreign students, and found no significant difference, but he did not correlate ESL grades with college grades. On the basis of these small samples and without giving explicit statistical information, the author concluded that intensive English programs have no significant effect on content course performance. This study was cited and used by Mossback (1977), along with two others he reviewed, to conclude that general ESL courses are "largely a waste of resources" (p. 318). Rosberg also quoted Mason when he described his own research into the effects of ESL courses on later community college study. He found no clear pattern to that relationship, but $54 \%$ of his subjects did not graduate from the two-year college.

Bostic (1981), with information from 154 students, found no significant difference between the academic performance of groups with and groups without resident ESL training. Dunn, in her study of 274 students at PSU, discovered no significant difference in academic 
performance between any of four English for Non-Native Residents (ENNR) groups and one control group. She qualified her findings by stating that the control group was not ideally matched in English ability to the ENNR groups. Neither Bostic nor Dunn compared intensive English class performance with subsequent academic achievement level.

Significant Positive Correlations. Wardlow, with 327 Moroccan students, and Zirpoli, Hallahan \& Kneedler (1988), with only 19 Indonesian students, both found English language training scores significantly related to later college performance. Wardlow, in fact, declared it as predictive as prior academic achievement in the students' home country. Woodbridge, in a study of 49 students, determined that GPAs for all ESL courses as well as that for each English skill area correlated significantly $(r=.46)$ with first-year college grades.

Significant Negative Correlations. Perry compared the university GPAs of groups with and groups without ESL courses in a study that combined data from the University of Minnesota and the University of Wisconsin, Madison. He found that the group without resident ESL training had a significantly higher mean GPA than the ESL group. Although his investigation used a large, full population--196 at Minnesota and 376 at Wisconsin--the value of the finding could be questioned on several grounds: 1) the ESL group 
included subjects with as little as one semester of intensive English anywhere in the U.S., 2) the actual differences in the means were small, according to the author (.11 at Wisconsin and .26 at Minnesota), and 3) there appeared to be few control variables for the different groups. Also, he did not calculate correlations of ESL and academic grades.

Shilling (1987) looked at data from 37 ENNR students and found that those who had the fewest years of what she called English language training entered the ENNR program at higher levels and then obtained higher content-course GPAs than did those with the most years of English language training. She admitted, however, that she encountered many problems in gathering data, and this may have influenced her results.

English for Specific Purposes. The preceding research considered general ESL as an independent variable. Mossback argued for the use of English for Specific Purposes (ESP) rather than general ESL. Other similar arguments are popular now, but I was not able to locate studies that 1) compared academic performance of students after ESP courses to that of others after general ESL courses, 2) compared the performance of students who had ESP training to those with no resident intensive English classes or 3) correlated accomplishment in ESP classes to that in later academic coursework. 
Adjunct Course Model. Although intensive English programs have been used for decades, the use of adjunct courses (academic classes in conjunction with ESL classes; the former provides the content for the latter) is relatively new and appears to be growing. Adamson (1990) speculated that ESL courses are not truly helpful to college-bound students because they generally do not teach academic skills, and he described adjunct pre-courses established to assist students in developing academic skills.

Apodaca, in her 1985 paper, stated:

The content of ESOL [English for Speakers of other Languages] courses is not adequate for the proper preparation of ESOL students to go into regular content-area and English courses..... our students need to be prepared beyond the interpersonal communication skills level to the academic language proficiency level. (p. 1)

She continued with a discussion of what she called a high intensity language training (HILT) curriculum in ESL that included subject area courses at all ESL levels.

Unfortunately, Adamson did not reveal the

effectiveness of the pre-courses, and Apodaca, although she asserted that the HILT program was successful, offered no evidence to that effect. 


\section{English Proficiency Tests}

Some two dozen studies are available that have correlated the Test of English as a Foreign Language (TOEFL) scores to academic achievement level, and their results have been nearly as mixed as have those that used some notion of English proficiency as a predictive variable. Grade correlations with English tests other than TOEFL have also been considered--some pre-admission and some post-admission.

No Significant Correlation. Hwang \& Dizney, in one of the first studies of the TOEFL as predictor of academic success, Sharon, Light, and Xu \& Mossop (1987), all found positive but insignificant correlations. Neither Zirpoli et al nor English (1988) found a significant relationship between TOEFL scores and GPAs.

TOEFL total and subtest scores correlated inversely to GPAs, but not significantly so, in a study by Woodbridge.

Adamson found that students who got high scores on English tests did not necessarily get high scores on content-course exams.

Significant Correlations. Burgess \& Greis discovered low but significant correlations between college grades and scores on both the Michigan and TOEFL. Dividing data from 176 international students into three groups--total GPAs, GPAs less freshman-level English, and GPAs without grades from less-verbal courses such as math, they found little 
difference in the correlations among these groups. Rosberg found high positive associations between both Michigan and TOEFL scores and community college GPAs. Although his sample was sizeable $(N=263)$, he revealed doubts about the study's meaningfulness because of the narrow GPA range: $82 \%$ of them fell between 1.76 and 2.50 , while only $1.14 \%$ were over 3.25 .

Total and subtest TOEFL scores were declared mildly predictive ( $r=.34$ to $r=.55)$ by Gue \& Holdaway (1973) and Hiel \& Aleamoni (1974), and the latter concluded that the TOEFI is as good a predictor of academic success for international students as the GRE is for American students. Harvey found TOEFL subtest scores and college grades significantly related. In comparing TOEFL subtest scores to later performance, Perry found the strongest relationship with GPA in the Reading/Vocabulary subtest, and Gue and Holdaway found the Reading/Vocabulary and Listening Comprehension scores correlated higher than did the others. Ironically, Perry found the Listening Comprehension scores to be the only ones not significantly associated with grades.

Using data from 1375 students at UCLA, Sugimoto found pre-admission test scores to be among the least predictive of numerous variables. The grades of writing tests in freshman-level English appeared to best predict academic 
performance in Burgess \& Greis' study. De Wolf (1980) found that students who received high verbal scores on a battery of pre-college English proficiency tests had higher first-year GPAs than did students with low scores, but her data were not analyzed statistically. English found high correlations $(r=.74$ and $r=.75)$ between the Test of written English (TWE) and second term GPAs for 21 students. First term GPAs, however, were not significantly related to the TWE scores.

other Test-Variable Relationships. Bostic and Perry both found TOEFL scores more strongly related to grades in what they considered less-verbal fields (math, engineering, music) than in more-verbal fields (English, sociology). Light et al, however, found the lowest TOEFL-GPA correlations with business majors and the highest with education and public affairs majors--the last two among the most verbal of fields. Harvey found a wide variation in the relationships of TOEFL scores with GPAs in major fields. In his study, GPAs rose with TOEFL scores for students in the areas of Arts \& Letters, Science, and Social Science. For Health \& Physical Education and Business Administration majors, however, GPAs declined as TOEFL scores increased. Some GPA differences were large, but he did not test the variations for significance. 
Graham (1987) declared that studies which include broader ranges of TOEFL scores and grades show higher correlations. Yet Perry found that eliminating the lowest $(<475)$ and the highest $(>649)$ scores produced the strongest correlations. Henning (1987) speculated that as students become more proficient in English, correlations between proficiency test scores and GPAs should become weaker.

Two studies, Hwang \& Dizney and Hosley \& Meredith (1979), found strong correlations between TOEFL scores and ESL course grades. The first compared the Listening Comprehension subtest scores with the composite grades on 15 quizzes in ESL courses; the second correlated total TOEFL scores to cumulative GPAs in ESL courses $(r=.66)$.

\section{Previous Scholastic Performance}

The inquiries into the relationship of prior academic preparation and college success all found positive, significant correlations except one: Covert \& Chansky. In comparing undergraduate GPAs (UGPAs) with graduate GPAs (GGPAS), they found a positive but not significant connection. Their data did indicate, however, that the higher UGPAs were more predictive than were the lower ones. Perry, Sharon, and Case \& Richardson all found UGPAS to be good predictors of GGPAs. Perry further investigated the relationship of UGPAs to GGPAs by field of study and revealed no significant differences in those correlations. 
Lukas (1989) discovered a significant relationship between previous scholastic performance and UGPAs. She also discovered that the mean GPA of her sample $(N=175)$ of international students was higher than that of all other students at her university. Sugimoto found a significant correlation between first semester UGPAs and later academic level of success.

Combined and other Variables

Lukas, Perry, Sugimoto and Woodbridge all examined nationality and found no significant relationship with college grades. In de Wolf's investigation, students from European countries other than the British Isles obtained a higher mean UGPA (2.88) than did those from African countries (2.55), but the difference was not statistically analyzed.

White \& Sedlacek and Boyer \& Sedlacek looked at noncognitive variables, using standardized personality tests and questionnaires, and determined that: a) in the first study, leadership skills and positive self-concept were strongly correlated with academic success and b) in the second, self-confidence and understanding of racism related best to GPAs.

Several researchers have either combined variables-usually prior scholastic performance and pre-admission test scores--or looked at multiple variables in order to 
determine the most predictive combination. Perry found that the TOEFL's Reading/Vocabulary subtest scores combined with academic preparation yielded the highest correlates. Information such as type (and country) of last school attended, amount of previous college, type of visa and residency status were examined by de Wolf and displayed some differences, but as mentioned before, she did not analyze her data statistically. Sugimoto reviewed 18 variables, using $C h i$ square analysis, and found no strong predictive ability. Case \& Richardson reviewed 28 possible predictive and moderator variables (factors that might influence predictive or criterion variables) and discovered that UGPA, GRE scores, ethnicity and gender were the best combined predictors. Shilling considered 37 factors (for ENNR students) and found the best correlation to academic performance among them was the presence or absence of the student's father combined with the type of diploma received. Major field of study was determined to be the only significant predictor of first semester GGPA by stover (1982), but most of his subject groups ranged from $\mathrm{N}=5$ to $\mathrm{N}=16$ - probably too small to be meaningful.

\section{CONCLUSIONS FROM THE LITERATURE REVIEW}

Boyer \& Sedlacek observed that, "Despite the extensive literature on international students, much remains to be learned about the variables related to their academic 
success" (p. 219). This review of relevant research seems to confirm that this is so, despite the appearance that recent investigations are of better quality than were many of the earlier ones.

\section{Measurement Problems}

Academic performance has been variously defined in the literature. Some researchers have simply rounded GPA to a four- or five-point scale (Perry; Dunn), while Rosberg used a full range of $G P A-$-for example, $2.45,3.87$, etc. At least one investigation defined academic success as a GPA greater than 2.00 (Shilling). Still others have combined GPA with number of credits completed (Light et al), or student retention--just staying in school (Boyer \& Sedlacek).

An additional complication is that studies of undergraduates have a broad range of GPA with which to work--from a theoretical 0.00 to a 4.00 , while those that use graduate students suffer from skewed GPAs between 2.50 or 3.00 and 4.00 .

The diverse operational definitions of academic performance alone could account for wide variation in results, but there are other factors that appear to contribute to the measurement problem. While some researchers have used hundreds of subjects (Bostic; Dunn), many have used numbers so low that validity is 
questionable--9, 11, 15, etc. (Mason; English). Other inquiries that used large samples or full populations and divided those into subgroups, frequently ended up with small or vastly unequal group sizes: 11 in one, 43 in another and 126 in yet another, for example (Stover; Lukas; \& Woodbridge). Still other researchers did no statistical analysis, or did so on only some of the data (de Wolf; Harvey).

Graham, in a discussion of the difficulties involved with relating English proficiency to academic success, points out that many variables not usually controlled or accounted for may distort the results. Number of classes taken, financial condition, and professorial attitudes can combine with difficulties of cultural adjustment or negative political developments in the students' home countries and create tremendous interference with their ability to function normally. A poignant recent example is the effect of the 1991 war in the Middle East on students from that area,

Finally, either most of the researchers whose work I reviewed did not account for many of the potential moderator variables (age, gender, nationality, prior education level, number of classes taken, and major field of study), or if they did, did not explain which ones and how. It seems to me other factors may account for some of the variation in findings. 
Since there seem to have been few thorough and meaningful investigations of how success in intensive English programs relates to later scholastic achievement, I perceive a need for the present study. 
CHAPTER III

\section{METHOD AND PROCEDURES}

\section{INTRODUCTION}

In this chapter I will first review the procedures and rationale used in the selection of subjects, will then discuss my operational definition of performance, and finally, will discuss the data and the manner in which it was grouped and statistically analyzed.

I attempted to select only those students who would fit into groups based upon what I considered moderator variables--variables that might have some effect on the relationship between ESL performance and academic performance, and which are described on the following page. The objective was to determine if some group(s) showed stronger ESL-academic GPA correlations than did others. As was stated in the conclusion of the preceding chapter, most studies either have not accounted for most of the variables I have, or the researchers did not make it clear which ones they did take into account. 
SUBJECTS

\section{Selection}

A list of undergraduate students at PSU who held F-1 (study) visas, who had entered the university since 1981, and who had last attended during or after fall, 1989, was initially compiled $(\mathrm{N}=375)$. Purged from this list were students a) whose first language is English; b) who had not completed at least one full-time quarter ( 9 credits minimum) of academic study; c) who had attended one year or more of high school in the U.S. or other English-speaking countries (to equalize pre-college exposure to formal English); d) who had taken between one and three ESL courses (to create a clearer distinction between ESL and non-ESL subjects); e) who had obtained the equivalent of a bachelor's degree in any country (there were too few of these to form a group of adequate size); and f) whose level of prior education, age, gender, nationality, PSU entry date, or general field of study (all variables I wished to consider) were indeterminate. The number of remaining subjects was 169 , divided into the main groups of ESL (77) and non-ESL (92).

For this study, I considered ESL performance to be the predictive variable and academic performance to be the criterion variable. In order to examine the effect of potential moderator variables, both ESL and non-ESL 
categories were further divided into intermediate groups of gender, the nature of their majors, age, nationality, previous English-speaking college experience, prior education level, TOEFL scores, date of PSU entry, and--for ESL students--the number of ESL classes taken. These intermediate groups were further divided into subgroups of male \& female; less-verbal \& more-verbal majors; under 24 \& 24 and older; Asian \& Middle-Eastern; some previous English-speaking college \& none; one quarter of prior college \& two quarters or more; TOEFL scores of ESL subjects--less than $500 \& 500$ and higher, and of non-ESL subjects--less than 551 \& 551 and higher; students entering PSU prior to fall, 1988 \& those entering fall, 1988 and later; and less than twelve ESL classes taken \& twelve or more. Figure 1 shows a diagram of this grouping hierarchy. It would have been ideal to divide subjects into specific nationality and specific major subgroups, but it was not possible to do so and maintain an adequate number of subjects per subgroup (N). Also, the status of English as an official language in some of the countries represented by the students might be a moderator variable; but again, to have eliminated or grouped subjects accordingly would have created subgroups that were too small.

The exact composition of the main groups, intermediate groups, and subgroups is shown in Appendices A\& B. 


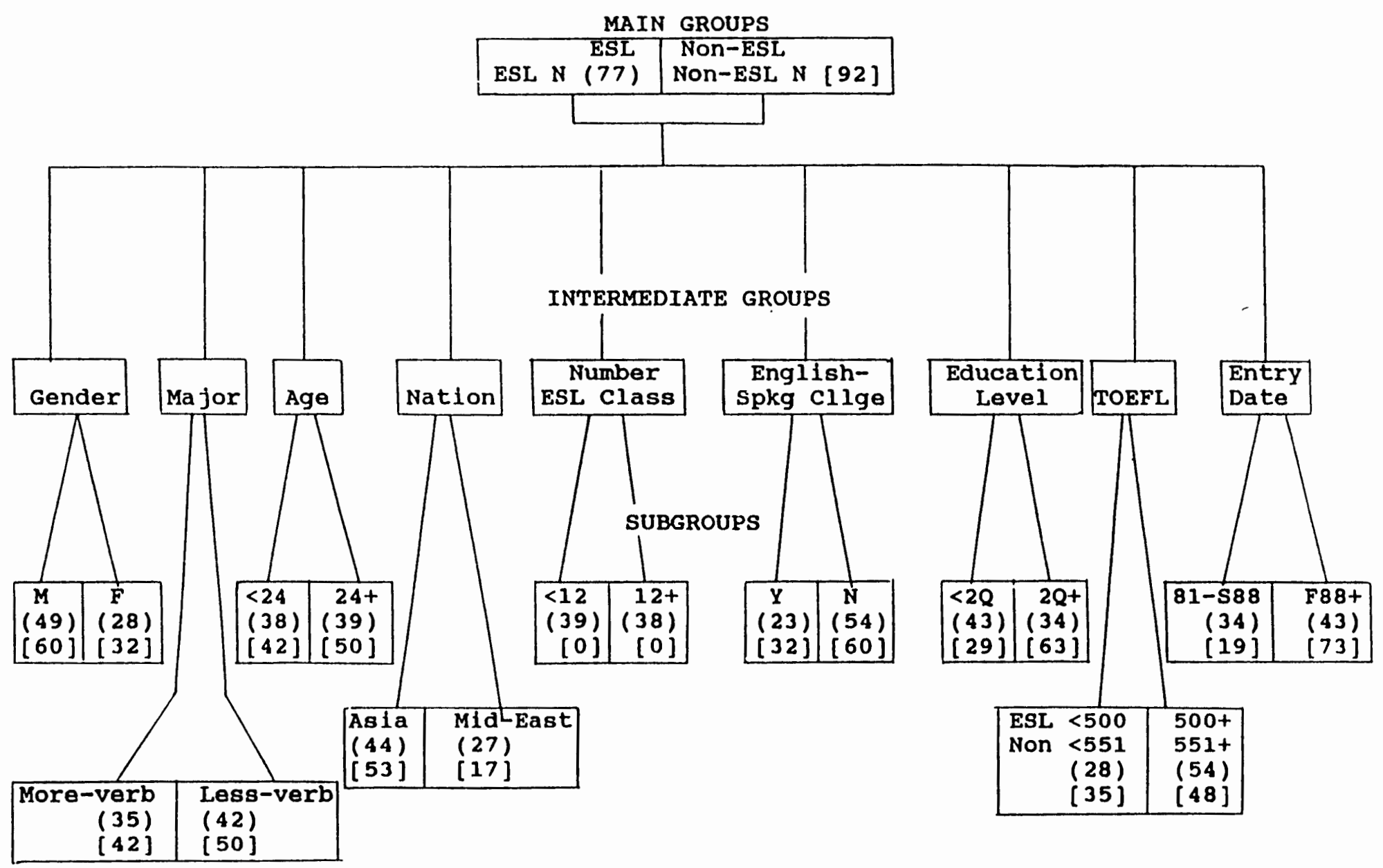

Figure 1. Subject grouping hierarchy. 
Highlights of Group Composition

Major Fields of study. Subjects were divided into more-verbal and less-verbal major subgroups based upon categories used by the International Education Data Collection Committee (1989):

More-Verbal

Business \& Management

Education

Foreign Languages

Letters

Psychology

Public Affairs

Social Science

Theater

\section{Less-Verbal}

Architecture/Environmental Design Computer \& Information Sciences Engineering Health Sciences Life Sciences Mathematics Visual/Performing Arts (except Theater)

Nearly $40 \%$ of both ESL and non-ESL students were majoring in subjects within the university's School of Business and about another $1 / 3$ of each in engineering or computer science. See Appendix A for exact numbers.

Gender and Age. The proportion of female students in both the ESL and non-ESL main groups was similar--slightly more than one third of each. Among ESL students, half were 24 years or older and half under 24 , while $54 \%$ of non-ESL students were 24 and over.

Nationality. The majority of international students at Portland State are from Asia, predominantly China (including Hong Kong and Taiwan) and Japan, while the 
second largest group was from the Middle East. This composition shows among the study's subjects overall, but with different proportions between the ESL and non-ESL groups: 60\% of the ESL students were from Asia and 35\% from the Middle East, while $58 \%$ of the non-ESL students were from Asia but only $19 \%$ from the Middle East. Put another way, less than half (45\%) of the Asian subjects were in the ESL group, while $61 \%$ of the Middle-Eastern subjects were in that group.

Prior Education. Only one-third of the ESL subjects had completed two quarters or more of college prior to arriving at PSU, while more than two-thirds of the non-ESL students had done so--some had completed several years.

In both the ESL and non-ESL groups, about one-third of the students had studied in a college where English had been the language of instruction prior to attending PSU.

other Factors. The differences between ESL and nonESL students' TOEFL scores and university entry dates were to some extent inherent in the nature of the variables themselves.

In the first case, for example, some ESL students were allowed to take some academic studies (through the special permission described in Chapter I, p. 3) with a TOEFL score of less than 500. In the non-ESL group, though, all students' scores were greater than 500, and thus they avoided the requirement for intensive English classes. 
Therefore, TOEFL scores ranged lower for ESL students than for non-ESL students.

In the second case, almost $80 \%$ of the non-ESL students had entered the university during the Fall of 1988 or later, but only $56 \%$ of the ESL students had done so. At least part of this difference is due to my subject selection stipulations regarding the first and last attendance dates: some of the ESL students attended intensive English classes for a year or more before beginning academic studies, but non-ESL students began them immediately.

As we will see in chapter IV, large differences in ESL and academic grade correlations appeared between some of the variable subgroups.

\section{DEFINING PERFORMANCE}

As I discussed briefly in Chapter II, several operational definitions of educational performance have been used in the literature. Most of them, however, have included grades. According to Hiel and Aleamoni, there are problems with this use of grades. One is that foreign students are sometimes graded more leniently than are American students. Another is that they reflect many things other than learning and achievement level for all students: things such as motivation, cultural adjustment, and stress. Yet another is that there does not seem to be 
a strong connection between the grades students receive and how well they succeed in the 'real' world. From a research point of view though, GPA is the most efficient and certainly the most easily quantifiable single measurement of performance (Lindvall, 1967; Perry, 1989).

\section{GPA CALCULATIONS}

GPA for this study was calculated differently from the official university calculations in two ways.

First, in cases where students received Ds or Fs but repeated those classes to improve their grades, I included both the lower grade and the one received from the repeat. (The university allows a student one repeat of a course in which a $D$ or $F$ was received; if a better grade is earned on the second attempt, this grade, rather than the first one, is used in the university's calculation). I included the lower grade in my computation because I considered those situations to better reflect actual performance in that a student who received, say, a D the first time through a class then $\mathrm{a} B$ on the second attempt did not perform as well as did one who received a $B$ the first time through. The second way in which my calculations differed from the university's was in the values assigned to pass-no pass (P-NP) grades. The number of grade points assigned to each credit hour of $P$ was 2.5 (essentially a $C+$ ) while NP was assigned 1 point. My justification for those numbers is as 
follows. Students generally, I think, take classes P-NP so they do not have to work as hard as they would to obtain an $A$ or B yet will not negatively affect their GPAs. It seems reasonable to me to assume that 'average' students will do average ( $\mathrm{C}$ or 2.00 ) work in a P-NP class, while better student.s will do slightly better work--perhaps B or Blevel. Thus the compromise of 2.5. As for the NP point assignment, few students actually receive an $F$ (in my subjects' transcripts, there is an average of one $F$ for every three transcripts--fewer than 60 Fs among thousands of grades). Therefore, I assumed the grade-level equivalent of work earning an NP would range mostly between D+ and D- and assigned 1 grade point to each credit hour. Although I do not think this point assignment is ideal, it was made necessary by the large number of ESL classes (27\% of the total) taken on a P-NP basis. To have rejected those students would have reduced the number of subjects to an inadequate level. Academic classes taken P-NP were treated the same way (14\% of the total). Although there is a difference in ratio between the ESL and academic classes taken P-NP, I believe that the equation is relatively well-balanced. Students who took many or most of their ESL classes P-NP also took a larger portion of their academic classes that way than did students who took all or most of their ESL classes for regular grades. Therefore, if the research GPAs were skewed because of the 
P-NP point assignment, they would most likely be skewed in the same direction for both the ESL and academic grades of the same students, giving credibility to the correlations. The grade distribution graphs in Appendix $C$ show little skewing.

\section{PROCEDURES}

\section{The Data}

Five different ESL GPAs were computed in order to analyze their relationships with academic GPAs. First, grades were averaged for all ESL classes taken by each student; then the same was done for each component-grammar, reading, writing, and speaking/listening. Twelve of the subjects had not taken a grammar class and thus had only four ESL GPAs.

Three different GPAs were calculated for academic classes: at the end of the first quarter, the end of the first year, and the end of the second year. Each of these included the credits and grade points of the previous computation, so they are cumulative. I originally proposed to calculate GPAs at the end of three years, but there were too few subjects who had completed three years.

In order to check performance differences between the main groups and subgroups, mean ESL and academic GPAs were calculated for each. 
The Statistical Tests

I performed several statistical tests. First, Pearson Correlation Coefficients (Pearson $r$ ) were calculated for the subjects' ESL and academic grades. Next, independent t-tests were performed on all GPAs between subgroups of the ESL students. Third, I ran independent $t$-tests on academic GPAs between the main ESL and non-ESL groups, then between subgroups within each. Fourth, correlations were calculated for the ESL students' TOEFL scores and ESL component (grammar, reading, writing, and speaking/listening) grades. Next, correlations were calculated for the subjects' TOEFL scores and three academic GPAs to ascertain the value of the TOEFL as a predictor of academic success. And finally, academic GPAs were compared by $t$-tests between students who scored lower and those who scored higher on the TOEFL.

The data distribution graphs in Appendix $C$ show that the data formed a relatively normal distribution, and therefore parametric tests such as the Pearson correlation and $t$-tests were appropriate to use. 
CHAPTER IV

RESULTS OF STATISTICAL TESTS

\section{INTRODUCTION}

In this chapter I will first show the Pearson Correlation coefficients $(r)$ found between ESL and academic GPAs for the entire ESL group and all subgroups. Second, I will show the results of the paired t-tests performed on ESL and academic grades. Then I will reveal the results of independent $t$-tests run on mean GPAs between subgroups within the main ESL group. Fourth, I will show the results of the same tests performed on academic GPAs between ESL and non-ESL students. Fifth, I will show the Pearson correlations between TOEFL scores and ESL component grades. And last, I will show the correlations between TOEFL scores and academic grades. Whenever the discussion states that no statistically significant relationship was found, the level of statistical significance is greater than $p=.05$, meaning that there is a more than 5\% probability that the relationship could occur by chance alone. I will, however, note correlations that appear strong even if they do not meet that level of probability. 
ESL AND ACADEMIC GPA RELATIONSHIPS

These relationships deal with my first four hypotheses. The first--that ESL GPAs would correlate significantly and positively with first year academic GPAs but not with those for the second year--was not confirmed. All together, there were 29 positive and statistically significant subgroup correlations between ESL and first year GPAs and 28 for the second year. Confusing the issue was the fact that nearly all the second year correlations were higher than those of the first year, yet most levels of statistical significance were lower for second year than for first year correlations. This is most likely a result of the relatively small number of subjects who had completed two years.

The second hypothesis--that correlations between academic grades and overall ESL and component grades (grammar, reading, writing, speaking/listening) would be the same--was not supported. Writing grades consistently showed the strongest connections, while reading grades showed the weakest. In fact, the reading component showed the largest portion of negative correlations; and they ranged as high as -.292 , although none reached statistical significance at an acceptable level. The speaking/listening component showed the second strongest relationship to academic grades, and grammar the third 
strongest (but least consistent, as I will discuss in Chapter V).

Hypothesis number three was that the ESL-academic grade correlations for students in more-verbal majors would be stronger than that for students in less-verbal majors, and this was supported. The differences here were quite dramatic as the tables on page 39 demonstrate.

Hypothesis number four--that there would be little difference in ESL and academic GPA correlations based upon the moderator variables of gender, age, and nationality-was rejected. There were large differences between the correlations of male and female subgroups, different age subgroups, Asian and Middle-Eastern subgroups, and subgroups based on number of ESL classes taken. These are exhibited in Tables II, III, and VI-XI and the scattergrams in Figures 2-5.

\section{Pearson correlation coefficients}

For the entire group overall ESL grades correlated weakly but significantly $(p \leq .003)$ with college grades at the end of both the first ( $\left.\begin{array}{ll}Y & 1\end{array}\right)$ and second ( $\left.\begin{array}{l}\text { 2 } \\ 2\end{array}\right)$ years. The only component grades that correlated significantly with first and second year grades, however, were those of writing. Grammar grades showed a very small but significant correlation to first year GPAs. No other significant relationships were found here; in fact, the 
correlation coefficients for ESL grades and first quarter grades were very low. These relationships are shown in Table I. (In Tables I-XIII, the correlations that met or exceeded my desired level of statistical significance are marked by *).

TABLE I

ESL-ACADEMIC GPA CORRELATIONS, ALL ESL STUDENTS

\begin{tabular}{|c|c|c|c|c|c|c|}
\hline Group & $+\mathrm{N}$ & $\pm+0 / A$ ESL & Grammar & Reading & Writing & spkg/Lstg \\
\hline Qtr & $77(65)$ & .126 & .175 & -.058 & .140 & .071 \\
\hline$p=$ & & .28 & .16 & .62 & .22 & .54 \\
\hline $\begin{array}{l}Y 1 \\
p=\end{array}$ & $73(61)$ & $\begin{array}{l}.314 * \\
<.01\end{array}$ & $\begin{array}{l}.261 * \\
.04\end{array}$ & $\begin{array}{c}.067 \\
.57\end{array}$ & $\begin{array}{l}.307 * \\
<.01\end{array}$ & $\begin{array}{l}.216 \\
.07\end{array}$ \\
\hline $\begin{array}{l}Y 2 \\
p=\end{array}$ & $44(32)$ & $\begin{array}{l}.329 * \\
.03\end{array}$ & $\begin{array}{c}.171 \\
.33 \\
\end{array}$ & $\begin{array}{c}.063 \\
.68 \\
\end{array}$ & $\begin{array}{r}.405 * \\
<.01 \\
\end{array}$ & $\begin{array}{r}.240 \\
.12 \\
\end{array}$ \\
\hline
\end{tabular}

By placing subjects into the moderator variable subgroups (gender, major, age, nationality, number of ESL classes taken, previous English-speaking college experience, prior education level, TOEFL scores, and PSU entry date) I discovered some sharp differences in correlations between them. The subgroups that showed the largest numbers of moderate to strong and significant correlations between ESL and academic grades were female, more-verbal major, under 24 years of age, Asian, twelve or more ESL classes, and previous English-speaking college 
experience. For the others, there were few statistically significant and meaningful relationships.

Gender. Male students' overall ESL, writing, and speaking/listening GPAs correlated lightly but significantly with their first year academic grades. All others were very low and three were negative. They are shown in Table II.

TABLE II

ESL-ACADEMIC GPA CORRELATIONS, MALE STUDENTS

\begin{tabular}{|c|c|c|c|c|c|c|}
\hline$\overline{\mathrm{GPA}}$ & $\mathbf{N}$ & $0 / A$ ESL & Grammar & Reading & Writing & Spkg/Lstg \\
\hline $\begin{array}{l}\text { Qtr } \\
p=\end{array}$ & $49(41)$ & $\begin{array}{c}.162 \\
.27\end{array}$ & $\begin{array}{l}.048 \\
.77\end{array}$ & $\begin{array}{c}-.036 \\
.80\end{array}$ & $\begin{array}{l}.170 \\
.24\end{array}$ & $\begin{array}{c}.063 \\
.67\end{array}$ \\
\hline $\begin{array}{l}\mathrm{Y} 1 \\
p=\end{array}$ & $46(38)$ & $\begin{array}{l}.393 \\
<.01\end{array}$ & $\begin{array}{l}.165 \\
.32\end{array}$ & $\begin{array}{l}.138 \\
.36\end{array}$ & $\begin{array}{l}.348 * \\
.02\end{array}$ & $.312 *$ \\
\hline $\begin{array}{l}Y 2 \\
p=\end{array}$ & $29(22)$ & $\begin{array}{r}.246 \\
.20 \\
\end{array}$ & $\begin{array}{c}-.083 \\
.71 \\
\end{array}$ & $\begin{array}{r}-.017 \\
.93 \\
\end{array}$ & $\begin{array}{c}.273 \\
.15 \\
\end{array}$ & $\begin{array}{c}.231 \\
.23 \\
\end{array}$ \\
\hline
\end{tabular}

The pattern of GPA relationships for female students was unusual by comparison to the other subgroups. While ESL grades correlated very little with college grades for either the first quarter or the first year, there was a strong correlation with second year grades. It is interesting to note by comparison that first quarter academic grades for these students showed a lower correlation to second year academic grades $(r=.527, p=.044)$ than did the ESL grades. In other words, their ESL grades were better predictors of long-term academic success than were their 
first quarter academic grades. By squaring the Pearson $r$ for the ESL-2nd year GPA correlations, we see that the relationship accounted for between $38 \%$ and $41 \%$ of grade variation. Pearson correlations are presented in Table III.

TABLE III

ESL-ACADEMIC GPA CORRELATIONS, FEMALE STUDENTS

\begin{tabular}{|c|c|c|c|c|c|c|}
\hline$\overline{\mathrm{GPA}}$ & $\mathbf{N}$ & O/A ESL & Grammar & Reading & Writing & Spkg/Lstg \\
\hline $\begin{array}{l}\text { Qtr } \\
p=\end{array}$ & $28(24)$ & $\begin{array}{l}.063 \\
.75\end{array}$ & $\begin{array}{c}.282 \\
.18\end{array}$ & $\begin{array}{c}-.034 \\
.86\end{array}$ & $\begin{array}{c}.023 \\
.91\end{array}$ & $\begin{array}{c}.142 \\
.47\end{array}$ \\
\hline $\begin{array}{l}Y 1 \\
p=\end{array}$ & $28(24)$ & $\begin{array}{l}.180 \\
.37\end{array}$ & $\begin{array}{c}.337 \\
.12\end{array}$ & $\begin{array}{c}.079 \\
.70\end{array}$ & $\begin{array}{c}.096 \\
.63\end{array}$ & $\begin{array}{l}.162 \\
.42\end{array}$ \\
\hline $\begin{array}{l}Y 2 \\
p=\end{array}$ & $15(12)$ & $\begin{array}{c}.617 * \\
.01\end{array}$ & $\begin{array}{l}.650 * \\
.02 \\
\end{array}$ & $\begin{array}{l}.638 * \\
.01\end{array}$ & $\begin{array}{l}.661 * \\
<.01\end{array}$ & $\begin{array}{c}.419 \\
.12 \\
\end{array}$ \\
\hline
\end{tabular}

Scattergrams illustrating the ESL-second academic year GPA correlations by gender are shown in Figures 2 and 3 . 


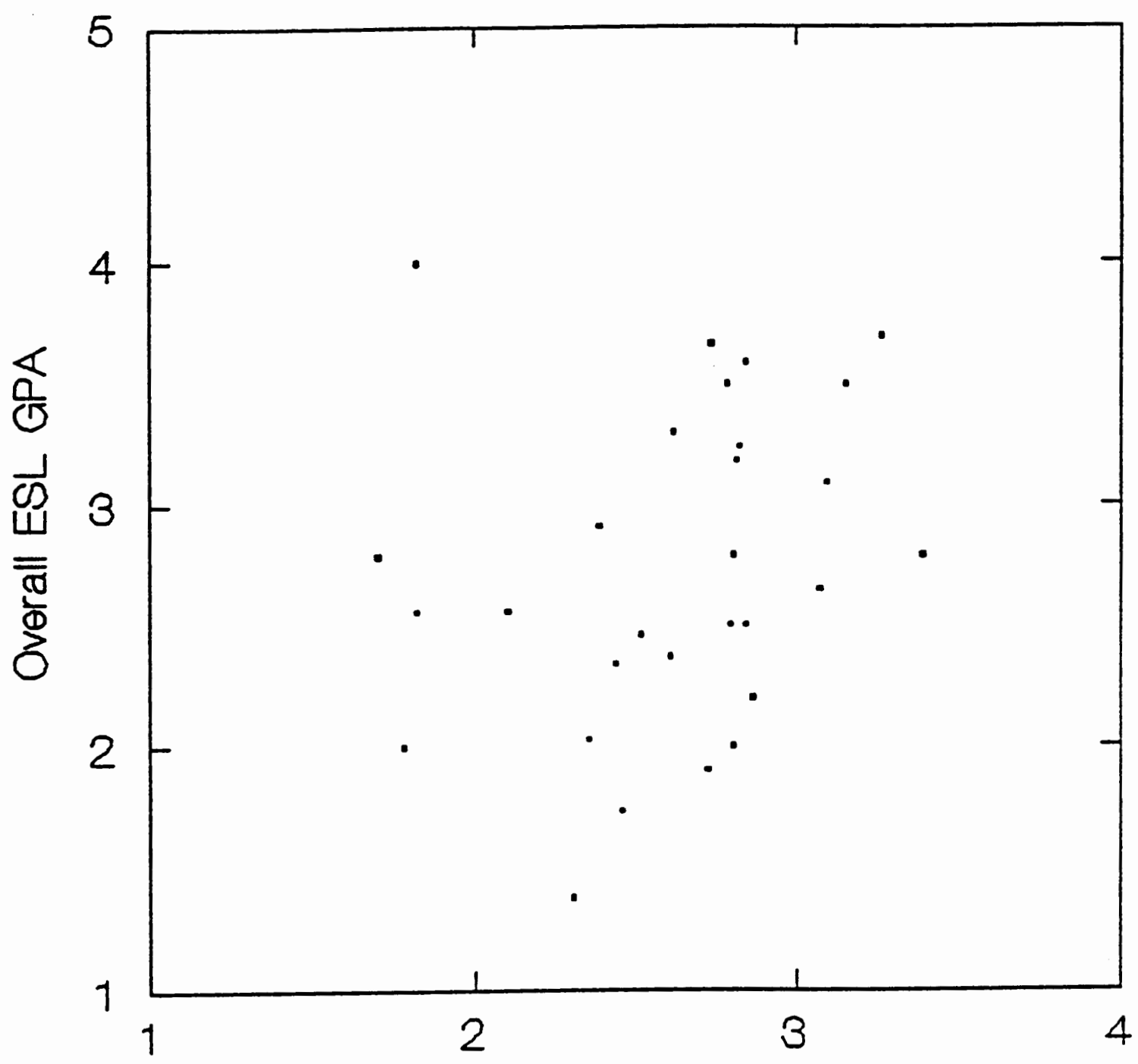

Second Year Academic GPA

Figure 2. Male ESL students' ESL-second academic year GPA correlations. 


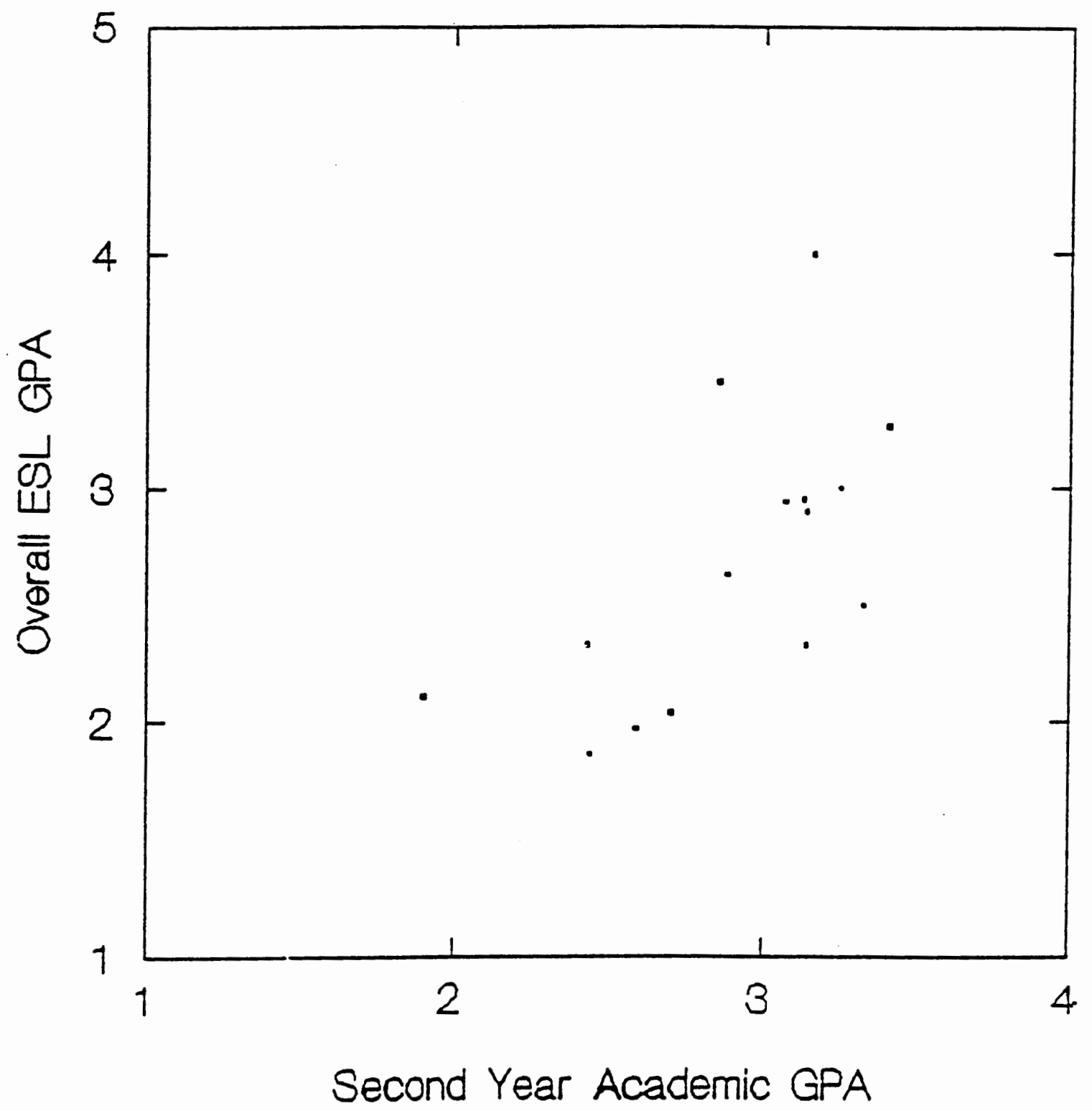

Fiqure 3. Female ESL students' ESL-second academic year GPA correlations.

Major. For students in less-verbal majors, there were neither large nor significant correlations between ESL and academic grades. See Table IV. 
TABLE IV

ESL-ACADEMIC GPA CORRELATIONS, LESS-VERBAL MAJOR STUDENTS

\begin{tabular}{|c|c|c|c|c|c|c|}
\hline$\underline{\mathrm{GPA}}$ & $N$ & $O / A$ ESL & Grammar & Reading & Writing & Spkg/Lstg \\
\hline $\begin{array}{l}\text { Qtr } \\
p=\end{array}$ & $42(35)$ & $\begin{array}{c}.021 \\
.90\end{array}$ & $\begin{array}{c}-.037 \\
.83\end{array}$ & $\begin{array}{c}-.141 \\
.37\end{array}$ & $\begin{array}{l}.005 \\
.97\end{array}$ & $\begin{array}{c}-.004 \\
.98\end{array}$ \\
\hline $\begin{array}{l}\mathrm{Y} 1 \\
p=1\end{array}$ & $41(34)$ & $\begin{array}{l}.294 \\
.06\end{array}$ & $\begin{array}{l}.105 \\
.55\end{array}$ & $\begin{array}{c}.054 \\
.74\end{array}$ & $\begin{array}{l}.249 \\
.12\end{array}$ & $\begin{array}{l}.224 \\
.16\end{array}$ \\
\hline $\begin{array}{l}Y 22 \\
p=\end{array}$ & $27(21)$ & $\begin{array}{c}.258 \\
.19 \\
\end{array}$ & $\begin{array}{l}.039 \\
.87 \\
\end{array}$ & $\begin{array}{c}-.045 \\
\quad .82 \\
\end{array}$ & $\begin{array}{c}.321 \\
.10\end{array}$ & $\begin{array}{l}.196 \\
.33 \\
\end{array}$ \\
\hline
\end{tabular}

The situation was quite different for students with more-verbal majors. Grades for overall ESL, grammar, and writing showed moderate-to-strong and statistically significant correlations with both first and second year GPAs. Additionally, grammar GPAs correlated moderately with first quarter grades. The strongest relationship was between writing and second year GPA, while the weakest significant correlation was between overall ESL and first year college grades. Neither speaking/listening nor reading grades showed significant correlations with any academic grades. The correlations are shown in Table $\mathrm{V}$.

\section{TABLE V}

ESL-ACADEMIC GPA CORRELATIONS, MORE-VERBAL MAJOR STUDENTS

\begin{tabular}{lclcccc}
\hline GPA & $\mathrm{N}$ & O/A ESL & Grammar & Reading & Writing & Spkg/Lstg \\
\hline $\mathrm{Qtr}$ & $35(30)$ & .256 & $.446 *$ & .106 & .288 & .163 \\
$p=$ & & .14 & .01 & .55 & .09 & .35 \\
$\mathrm{Y} 1$ & $32(27)$ & $.368 *$ & $.530 *$ & .157 & $.408 *$ & .204 \\
$p=$ & & .04 & 0.01 & .39 & .02 & .26 \\
$\mathrm{Y} 2$ & $17(13)$ & $\begin{array}{l}.505 * \\
.04\end{array}$ & .539 & .437 & $.588 *$ & .336 \\
$p=$ & & & .06 & .08 & .01 & .19 \\
\hline
\end{tabular}


Age. Students 24 years and older showed neither high nor significant correlations; and six of the fifteen were negative, as Table VI shows.

TABLE VI

ESL-ACADEMIC GPA CORRELATIONS, STUDENTS 24 YEARS \& OLDER

\begin{tabular}{lcccccc}
\hline $\mathrm{GPA}$ & $\mathrm{N}$ & $\mathrm{O} / \mathrm{A}$ ESL & Grammar & Reading & Writing & Spkg/Lstg \\
\hline $\mathrm{Qtr}$ & $39(30)$ & -.143 & .041 & -.255 & -.089 & -.144 \\
$p=$ & & .38 & .82 & .12 & .59 & .38 \\
$\mathrm{Y} 1$ & $39(30)$ & .152 & .146 &.- .038 & .182 & .023 \\
$p=$ & & .36 & .44 & .82 & .27 & .89 \\
$\mathrm{Y} 2$ & $30(22)$ & .241 & .130 & -.009 & .332 & .128 \\
$p=$ & & .20 & .56 & .96 & .07 & .50 \\
\hline
\end{tabular}

Subjects younger than 24 years showed several

moderate-to-strong and statistically significant relationships. Overall ESL GPAs and writing GPAs correlated significantly with all three academic GPAs; the writing-second year connection is strong enough to account for nearly half $\left(r^{2}=45 \%\right)$ of GPA variation. Grammar grades show a low but significant correlation with first year college grades, and speaking/listening GPAs correlated significantly with both first and second year academic GPAs. Reading grades were not significantly related to any academic grades. See Table VII. 
TABLE VII

ESL-ACADEMIC GPA CORRELATIONS, STUDENTS UNDER 24 YEARS

\begin{tabular}{|c|c|c|c|c|c|c|}
\hline$\overline{\mathrm{GPA}}$ & $\mathrm{N}$ & $0 / A$ ESL & Grammar & Reading & Writing & Spkg/Lstg \\
\hline $\begin{array}{l}\text { Qtr } \\
p=\end{array}$ & $38(35)$ & $\begin{array}{l}.476 * \\
<.01\end{array}$ & .311 & $\begin{array}{c}.300 \\
.07\end{array}$ & $\begin{array}{l}.477 * \\
<.01\end{array}$ & $\begin{array}{l}.308 \\
.06\end{array}$ \\
\hline $\begin{array}{l}Y \\
p=\end{array}$ & $34(31)$ & $\begin{array}{l}.539 * \\
<.01\end{array}$ & $\begin{array}{l}.366 * \\
.04\end{array}$ & $\begin{array}{l}.278 \\
.11\end{array}$ & $\begin{array}{l}.514 * \\
<.01\end{array}$ & $\begin{array}{l}.430 * \\
.01\end{array}$ \\
\hline $\begin{array}{l}Y 2 \\
p=\end{array}$ & $14(12)$ & $\begin{array}{c}.571 * \\
.03\end{array}$ & $\begin{array}{l}.311 \\
.33\end{array}$ & $\begin{array}{l}.355 \\
.21\end{array}$ & $\begin{array}{l}.668 * \\
<.01\end{array}$ & $.552 *$ \\
\hline
\end{tabular}

Nationality. Middle-Eastern students showed an unusual trend. More than half of their correlations were negative, with the strong negative correlation between grammar and second year GPAs reaching a $p=.065$ level of statistical significance--only a little less than the minimum level I chose. Additionally, all their positive correlations were very weak. The figures are shown in Table VIII.

TABLE VIII

ESL-ACADEMIC GPA CORRELATIONS, MIDDLE EASTERN STUDENTS

\begin{tabular}{lcccccc}
\hline GPA & $\mathrm{N}$ & O/A ESL & Grammar & Reading & Writing & Spkg/Lstg \\
\hline $\begin{array}{l}\text { Qtr } \\
p=\end{array}$ & $27(21)$ & -.119 & .023 & -.292 & -.180 & -.174 \\
& & .56 & .92 & .14 & .37 & .39 \\
$\mathrm{Y} 1$ & $26(20)$ & .206 & -.116 & -.035 & .276 & .048 \\
$p=$ & & .31 & .63 & .87 & .17 & .82 \\
$\mathrm{Y} 2$ & $17(12)$ & .124 & -.548 & -.148 & .157 & .116 \\
$p=$ & & .64 & .07 & .57 & .55 & .66 \\
\hline
\end{tabular}

For the Asian students, ten of fifteen correlations were statistically significant. Both overall ESL grades 
and writing grades correlated moderately with all three academic grades. Additionally, grammar GPAs correlated moderately with both first and second year GPAs, reading correlated moderately with second year GPAs, and speaking/listening grades correlated lower but still significantly with first year academic grades. The correlations are shown in Table IX.

\section{TABLE IX}

ESL-ACADEMIC GPA CORRELATION, ASIAN STUDENTS

\begin{tabular}{|c|c|c|c|c|c|c|}
\hline$\overline{\text { GPA }}$ & $\mathrm{N}$ & $0 / A$ ESL & Grammar & Reading & Writing & Spkg/Lstg \\
\hline $\begin{array}{l}\text { Qtr } \\
p=\end{array}$ & $44(39)$ & $.315 *$ & .213 & $\begin{array}{l}.237 \\
.12\end{array}$ & $\begin{array}{l}.361 \star \\
.02\end{array}$ & $\begin{array}{l}.248 \\
.10\end{array}$ \\
\hline $\begin{array}{l}\mathrm{Y} \\
p=\end{array}$ & $42(37)$ & $\begin{array}{l}.429 * \\
<.01\end{array}$ & $\begin{array}{l}.406 * \\
.01\end{array}$ & .231 & $\begin{array}{l}.403 * \\
<.01\end{array}$ & $\begin{array}{l}.370 * \\
.02\end{array}$ \\
\hline $\begin{array}{l}Y 2 \\
p=\end{array}$ & $24(20)$ & $\begin{array}{c}.450 * \\
.03 \\
\end{array}$ & $\begin{array}{l}.504 * \\
.02\end{array}$ & $\begin{array}{l}.434 * \\
.03\end{array}$ & $\begin{array}{l}.561 * \\
<.01\end{array}$ & $\begin{array}{l}.200 \\
.35\end{array}$ \\
\hline
\end{tabular}

Number of ESL Classes. Students who had taken less than twelve ESL classes had no statistically significant relationships between ESL and college grades, and seven of the fifteen correlations were negative. See Table $x$. 
TABLE X

ESL-ACADEMIC GPA CORRELATIONS, STUDENTS WITH FEWER THAN 12 ESL CLASSES

\begin{tabular}{lcccccc}
\hline GPA & $\mathrm{N}$ & O/A ESL & Grammar & Reading & Writing & Spkg/Lstg \\
\hline $\begin{array}{l}\text { Qtr } \\
p=\end{array}$ & $38(28)$ & -.063 & -.095 & -.277 & .021 & -.079 \\
& & .71 & .63 & .09 & .90 & .64 \\
$\mathrm{Y} 1$ & $37(27)$ & .200 & .088 & -.103 & .199 & .167 \\
$p=$ & & .24 & .66 & .54 & .29 & .32 \\
$\mathrm{Y} 2$ & $22(14)$ & .234 & -.302 & -.089 & .342 & .222 \\
$p=$ & & .30 & .29 & .70 & .12 & .32 \\
\hline
\end{tabular}

The largest number of moderate to strong and significant correlations were found among subjects who had taken more than eleven ESL classes. The only three that did not reach my desired level of statistical significance were those for the speaking/listening component. The figures are shown in Table XI.

TABLE XI

ESL-ACADEMIC GPA CORRELATIONS, STUDENTS WITH 12 OR MORE ESL CLASSES

\begin{tabular}{|c|c|c|c|c|c|c|}
\hline$\overline{\mathrm{GPA}}$ & $\mathrm{N}$ & $O / A$ ESL & Grammar & Reading & Writing & Spkg/Lstg \\
\hline $\begin{array}{l}\text { Qtr } \\
p=\end{array}$ & $39(37)$ & $\begin{array}{l}.388 * \\
.02\end{array}$ & $\begin{array}{l}.359 * \\
.03\end{array}$ & $\begin{array}{l}.360 * \\
.02\end{array}$ & $.327 *$ & $\begin{array}{c}.289 \\
.07\end{array}$ \\
\hline $\begin{array}{l}Y=1 \\
p=\end{array}$ & $36(34)$ & $\begin{array}{l}.522 * \\
<.01\end{array}$ & $\begin{array}{l}.425 * \\
.01\end{array}$ & $\begin{array}{l}.512 * \\
<.01\end{array}$ & $\begin{array}{l}.517 * \\
<.01\end{array}$ & $\begin{array}{l}.321 \\
.06\end{array}$ \\
\hline $\begin{array}{l}Y 2 \\
p=\end{array}$ & $22(20)$ & $\begin{array}{l}.566 * \\
<.01\end{array}$ & $\begin{array}{l}.555 * \\
.01\end{array}$ & $\begin{array}{l}.566 * \\
<.01 \\
\end{array}$ & $\begin{array}{l}.616 * \\
<.01\end{array}$ & $\begin{array}{c}.341 \\
.12 \\
\end{array}$ \\
\hline
\end{tabular}

Similar to the situation with female subjects, the writing-second year GPA correlation was nearly as high as the correlation between first quarter and second year 
academic GPAS $(r=.625)$, and both were significant at $p=.002$. ESL performance appeared to be as strongly indicative of long-term academic success for this subgroup as were their first quarter academic grades. The scattergrams in Figures 3 and 4 illustrate the ESL-second year correlations for these subgroups.

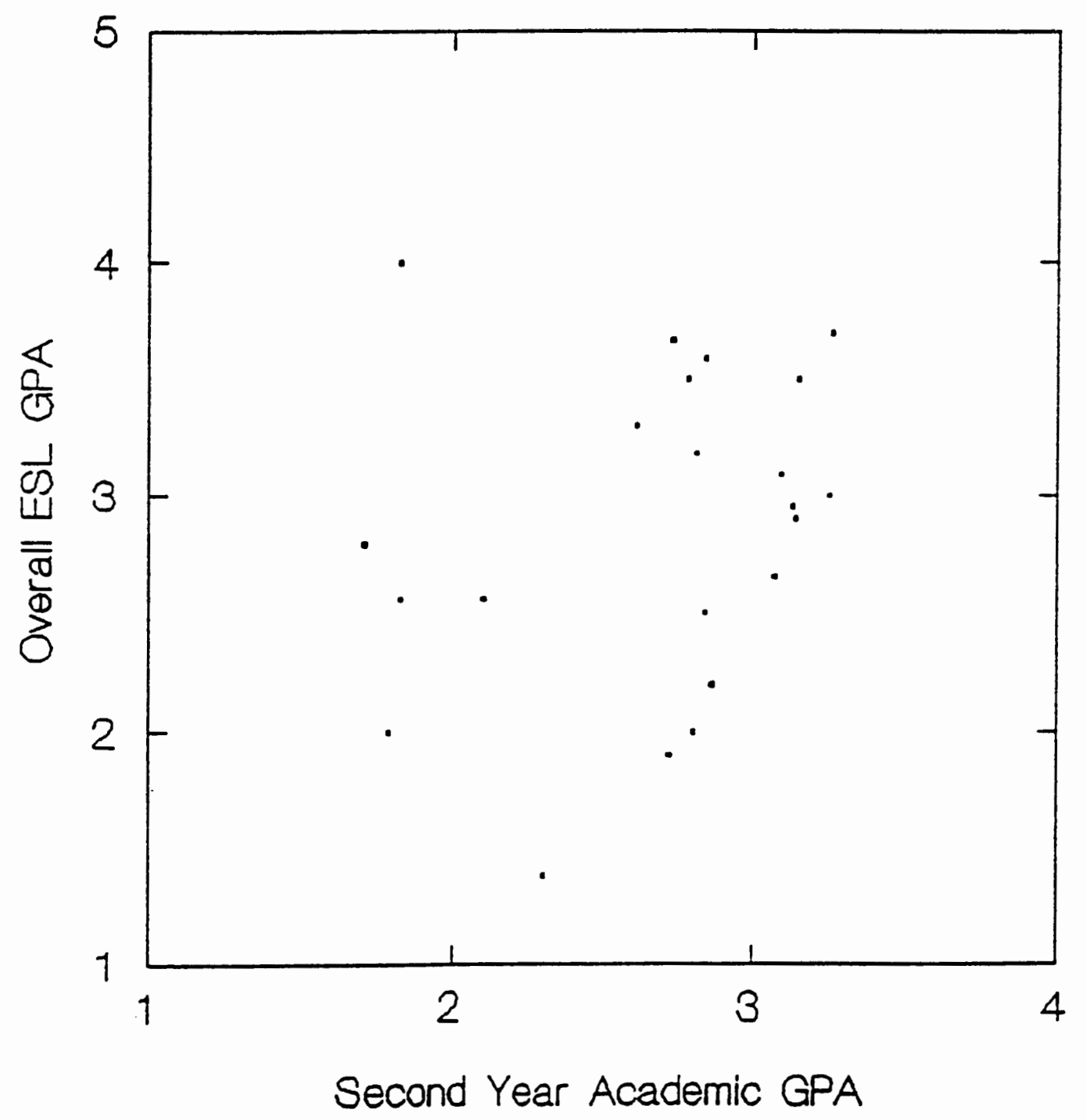

Figure 4. ESL-2nd year academic GPA correlations: students who took less than 12 ESL classes. 


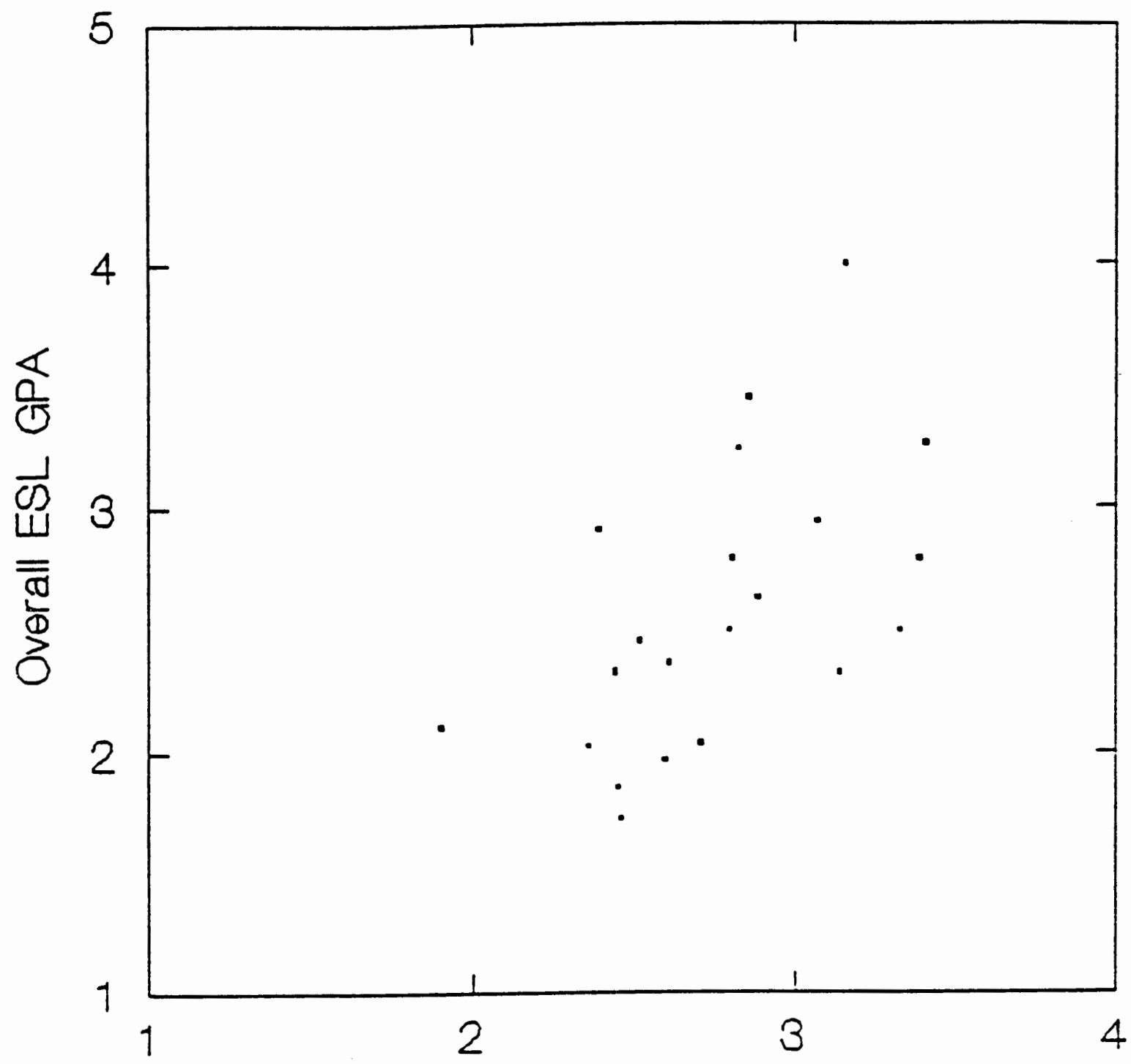

Second Year Academic GPA

Figure 5. ESL-2nd year academic GPA correlations: students who took 12 or more ESL class

Previous English-Speaking College Experience. There were weak relationships between the ESL and college grades of students who had none of this experience: three were negative, and none of the positive relationships were significant. See Table XII. 
TABLE XII

ESL-ACADEMIC GPA CORRELATIONS, STUDENTS WITH NO PREVIOUS ENGLISH-SPEAKING COLLEGE EXPERIENCE

\begin{tabular}{lcccccc}
\hline GPA & $\mathrm{N}$ & $\mathrm{O} / \mathrm{A}$ ESL & Grammar & Reading & Writing & Spkg/Lstg \\
$\begin{array}{c}\text { Qtr } \\
p=\end{array}$ & $54(48)$ & .145 & .100 & -.084 & .141 & .133 \\
& & .30 & .50 & .55 & .31 & .34 \\
$\mathrm{Y} 1$ & $59(44)$ & .217 & .175 & -.043 & .211 & .149 \\
$p=$ & & .13 & .26 & .77 & .14 & .30 \\
$\mathrm{Y} 2$ & $33(27)$ & .207 & .057 & -.146 & .307 & .206 \\
$p=$ & & .25 & .78 & .42 & .08 & .25 \\
\hline
\end{tabular}

students who had previously attended institutions where English is the language of instruction showed some grade relationships that were positive, strong, and statistically significant. Overall ESL and writing grades were strongly related to both first and second year academic grades. Reading GPAs correlated strongly with second year grades, and speaking/listening grades correlated moderately with second year college grades. Grammar GPAs correlated strongly with second year grades but the relationship was not statistically significant, probably because of the small number of subjects in that category (7). The relationships are shown in Table XIII.

This was one of three subgroups (along with female students and those who had taken 12 or more ESL classes) in which the correlation between writing and second year GPA was as strong as or stronger than that between first quarter and second year academic grades $(r=.574, p=.065)$. 
TABLE XIII

ESL-ACADEMIC GPA CORRELATIONS, STUDENTS WITH SOME PREVIOUS ENGLISH-SPEAKING COLLEGE EXPERIENCE

\begin{tabular}{lcccccc}
\hline GPA & $\mathrm{N}$ & O/A ESL & Grammar & Reading & Writing & Spkg/Lstg \\
$\begin{array}{l}\text { Qtr } \\
p=\end{array}$ & $23(17)$ & .244 & .378 & .140 & .256 & .120 \\
& & .26 & .14 & .52 & .24 & .59 \\
$\mathrm{Y} 1$ & $23(17)$ & $.601 *$ & .438 & .391 & $.522 *$ & $.495 *$ \\
$P=$ & & $<.01$ & .08 & .07 & .01 & .02 \\
$\mathrm{Y} 2$ & $11(7)$ & $.629 *$ & .590 & $.656 *$ & $.640 *$ & .381 \\
$P=$ & & .04 & .16 & .03 & .03 & .25 \\
\hline
\end{tabular}

Prior Education Level. The subgroups here showed differences that were similar to but smaller than those in the English-speaking college subgroup, and logically so: the subgroup with less than two quarters of prior college included the subgroup with no English-speaking college attendance, while the subgroup with two quarters or more of prior college included those with similar amounts of English-speaking university experience.

The subgroup with less than two quarters of prior college had only one statistically significant but rather low correlation--that of writing and first year grades $(.320, p=.041)$. This does not appear to be a strong relationship, accounting for only about $10 \%$ of grade variation.

The students' grades in the other subgroup showed two stronger connections: grammar and writing correlated with 
second year GPAs at $r=.552(p=.027)$ and $r=.465(p=.034)$, respectively.

TOEFL Scores. There was little difference in ESLacademic grade correlation between students who scored less than 500 and those who scored 500 or higher on the TOEFL. The first subgroup had virtually no statistically significant correlations and six of them were negative; the second group had four negative correlations, but three others that were both positive and significant: writing grades correlated with both first and second year college grades at $r=.335(p=.028)$ and $r=.401(p=.031)$, respectively; and overall ESL GPAs correlated with first year GPAs at $r=.316$, significant at $p=.039$.

PSU Entry Date. Students who entered the ESL program fall term, 1988 or later showed four negative (but not statistically significant) correlations and only one that was both positive and significant--between writing and first quarter academic grades $(r=.307, p=.045)$. Those who entered the ESL program prior to fall term, 1988, showed three negative, non-significant correlations and three that were both positive and significant: writing grades correlated lightly with first year grades $(r=.389, p=.023)$ and moderately with second year grades $(r=.467, p=.012)$; and overall ESL grades correlated lightly with first year 
grades $(r=.344, p=.046)$ and second year grades $(r=.399$, $p=.040)$.

MEAN GPA DIFFERENCES BETWEEN ESL SUBGROUPS

\section{ESL Grades}

There were only three pairs of subgroups that showed statistically significant differences between mean ESL GPAS: previous English-speaking college experience, TOEFL scores, and number of ESL classes taken.

Previous English-speaking College Experience. The average ESL grades of students with this experience was 2.38 (standard deviation $[S D]=.602$ ), while that of students without that experience was $2.79(\mathrm{SD}=.556)$, significance level $p=.005$. This is discussed in Chapter $\mathrm{V}$.

TOEFL Scores. Students whose final TOEFL scores were less than 500 had a mean GPA of 2.35 (SD of .423), while those whose final scores were 500 or higher had a mean GPA of 2.89 (SD of .597), significant at $p<.0005$. This finding reflects the relationship found between TOEFL scores and ESL grades as described later in this chapter--students whose ESL grades were very low seem to have scored lower than the others on the TOEFL.

Number of ESL Classes. Although the GPAs for the subgroups here differed by a mean of .27 and was statistically significant, there can be little meaning 
attached to the finding. The difference is in large part a function of the number of classes taken: the students who do poorer take more classes and repeat some to improve grades (eighteen of the thirty-eight students in this subgroup had taken more than 16 ESL classes--the total of all four component classes at all four levels). As I described in chapter III, both the lower and higher grades were calculated into GPA, lowering the ESL grade average for subjects who took the largest number of ESL classes.

other Subgroups. Mean ESL GPAs were virtually identical for the pairs of subgroups within the intermediate groups of gender, major, age, and nationality. (The subjects from the Middle East, however, showed a SD of .720 , while those from Asia showed one of .495). Students with more prior education did slightly better than those with less $(2.62, S D=.543$ and $2.53, S D=.611$, respectively) but the difference was not statistically significant. Similarly, students who had entered the ESL program during or after fall, 1988 had slightly higher mean grade than did those who entered earlier--2.61 $(S D=.498)$ and 2.52 $(S D=.532)$, respectively, but again not significantly so.

\section{Academic Grades}

Gender. With respect to both first and second year grades, the female students did significantly better than 
did the males, and for the first year, with a lower standard deviation. See Table XIV.

TABLE XIV

MEAN ACADEMIC GPA DIFFERENCES BY GENDER, ESL STUDENTS

\begin{tabular}{|c|c|c|c|c|c|}
\hline Subgroup & & $\mathrm{N}$ & Mean & SD & $p$ \\
\hline 1st Yr - & $\begin{array}{l}\text { Male } \\
\text { Female }\end{array}$ & $\begin{array}{l}47 \\
27\end{array}$ & $\begin{array}{l}2.55 \\
2.92\end{array}$ & $\begin{array}{l}.588 \\
.392\end{array}$ & .005 \\
\hline 2nd $\mathrm{Yr}$ & $\begin{array}{l}\text { Male } \\
\text { Female }\end{array}$ & $\begin{array}{l}29 \\
15 \\
\end{array}$ & $\begin{array}{l}2.61 \\
2.90 \\
\end{array}$ & $\begin{array}{l}.443 \\
.414 \\
\end{array}$ & .043 \\
\hline
\end{tabular}

Nationality. Although all three GPAs for these two subgroups were quite different, only the difference between first year grades were significant, as shown in Table XV.

TABLE XV

MEAN ACADEMIC GPA DIFFERENCES BY NATIONALITY, ESL STUDENTS

\begin{tabular}{|c|c|c|c|c|c|c|}
\hline \multicolumn{3}{|c|}{ Subgroup } & $\mathrm{N}$ & Mean & SD & $p$ \\
\hline Qtr & $\begin{array}{r}-2 \\
1\end{array}$ & $\begin{array}{l}\text { Asian } \\
\text { Mid-Eastern }\end{array}$ & $\begin{array}{l}44 \\
27\end{array}$ & $\begin{array}{l}2.86 \\
2.62\end{array}$ & $\begin{array}{l}.514 \\
.530\end{array}$ & .072 \\
\hline $1 s t$ & Yr & $\begin{aligned} \text { - Asian } & \text { Mid-Eastern }\end{aligned}$ & $\begin{array}{l}42 \\
26\end{array}$ & $\begin{array}{l}2.85 \\
2.55\end{array}$ & $\begin{array}{l}.399 \\
.401\end{array}$ & .004 \\
\hline 2nd & Yr & $\begin{aligned} & \text { - Asian } \\
& \text { Mid-Eastern } \\
&\end{aligned}$ & $\begin{array}{l}24 \\
17 \\
\end{array}$ & $\begin{array}{l}2.81 \\
2.58 \\
\end{array}$ & $\begin{array}{l}.452 \\
.389 \\
\end{array}$ & .087 \\
\hline
\end{tabular}

Prior Education Level. The subgroups here showed no difference for the first quarter, but a considerable difference thereafter. The data for years one and two are shown in Table XVI. 
TABLE XVI

MEAN ACADEMIC GPA DIFFERENCES BY PRIOR EDUCATION LEVEL, ESL STUDENTS

\begin{tabular}{rlllll}
\hline Subgroup & & $\mathrm{N}$ & Mean & SD & $p$ \\
\hline Ist Yr & $<2$ Qtr & 41 & 2.61 & .453 & \\
& $\geq 2$ Qtrs & 32 & 2.86 & .421 & .017 \\
2nd Yr - & 2 Qtr & 23 & 2.62 & .465 & \\
& $\geq 2$ Qtrs & 21 & 2.80 & .423 & .175 \\
\hline
\end{tabular}

TOEFL Scores. The subgroups here revealed both sizeable and statistically significant differences in academic GPAs. Students with final TOEFL scores of less than 500 had lower academic grades than did those who scored 500 or above--significantly so for both the first quarter and the first year, as shown in Table XVII. This finding seems to contradict the very weak Pearson correlations between TOEFL scores and academic grades shown later in this chapter and will be discussed in chapter v.

TABLE XVII

MEAN ACADEMIC GPA DIFFERENCES BY TOEFL SCORE GROUPING, ESL STUDENTS

\begin{tabular}{ccccc}
\hline Subgroup & N & Mean & SD & $p$ \\
\hline Qtr-lower scores & 28 & 2.56 & .510 & \\
higher scores & 43 & 2.84 & .584 & .04 \\
Yr1-lower scores & 26 & 2.58 & .445 & \\
higher scores & 43 & 2.80 & .441 & .05 \\
Yr2-lower scores & 13 & 2.56 & .456 & .18 \\
higher scores & 29 & 2.76 & .439 & \\
\hline
\end{tabular}


other. Subgroups within gender, nationality, prior education level, and TOEFL scores were the only ones between which significant academic GPA differences were found. But there was a pattern within one of the intermediate groups--number of ESL classes--that, although not statistically significant, might in some way be related to the ESL program: the grades of students who had taken fewer than twelve ESL classes fell from the end of the first quarter to the end of the second year, while those of students who had taken 12 or more ESL classes rose slightly during the same period. See Table XVIII.

TABLE XVIII

MEAN ACADEMIC GPAS BY NUMBER OF ESL CLASSES

\begin{tabular}{llcc}
\hline Subgroup & Qtr & 1st Yr & 2nd Yr \\
\hline Less than 12 & 2.77 & 2.71 & 2.67 \\
12 or more & 2.68 & 2.73 & 2.75 \\
\hline
\end{tabular}

Although the difference between first academic quarter and second year grades of the group with less than 12 ESL classes was not statistically significant $(p=.496)$, this pattern, combined with that of non-ESL students (see Table XXIII, on page 57) showing a greater level of statistical significance, suggests that the length of time spent in the intensive English program may have some relationship to the long-term academic success of its students. This will be discussed further in chapter V. 
COMPARING GPAS OF ESL AND NON-ESL STUDENTS

My fifth and last hypothesis was that there would be no statistically significant difference between the mean GPA of the ESL students and the non-ESL students. This was supported for the second year, but not for the first quarter or first year. Additionally, comparing subgroups across the main groups revealed variations in those differences, as Tables XX through XXII show.

\section{Full Groups}

There were both sizeable and statistically significant differences between the mean GPAs of the main groups at the end of the first quarter and first year. Although there was still a difference at the end of the second year, it had narrowed and was no longer statistically significant, as shown in Table XIX.

TABLE XIX

MEAN ACADEMIC GPA DIFFERENCES BETWEEN ESL AND NON-ESL STUDENTS

\begin{tabular}{|c|c|c|c|c|c|}
\hline Group & & $\mathbf{N}$ & Mean & SD & $p$ \\
\hline Qtr - & $\begin{array}{l}\text { ESI } \\
\text { non-ESL }\end{array}$ & $\begin{array}{l}77 \\
92\end{array}$ & $\begin{array}{l}2.74 \\
3.00\end{array}$ & $\begin{array}{l}.559 \\
.564\end{array}$ & .003 \\
\hline 1st $\mathrm{Yr}$ & $\begin{aligned}- & \text { ESL } \\
& \text { non-ESL }\end{aligned}$ & $\begin{array}{l}74 \\
92\end{array}$ & $\begin{array}{l}2.68 \\
2.93\end{array}$ & $\begin{array}{l}.551 \\
.499\end{array}$ & .003 \\
\hline 2nd $\mathrm{Yr}$ & $\begin{array}{l}\text { - ESL } \\
\text { non-ESL }\end{array}$ & $\begin{array}{l}44 \\
63 \\
\end{array}$ & $\begin{array}{l}2.71 \\
2.82 \\
\end{array}$ & $\begin{array}{r}.450 \\
.612 \\
\end{array}$ & .259 \\
\hline
\end{tabular}


Gender

The women students within the ESL and non-ESL groups had average grades that were within .17 of each other with no statistical significance and little contrast in standard deviations. The men, though, showed larger differences as seen in Table $\mathrm{XX}$.

TABLE XX

MEAN ACADEMIC GPA DIFFERENCES BETWEEN ESL AND NON-ESL MALE STUDENTS

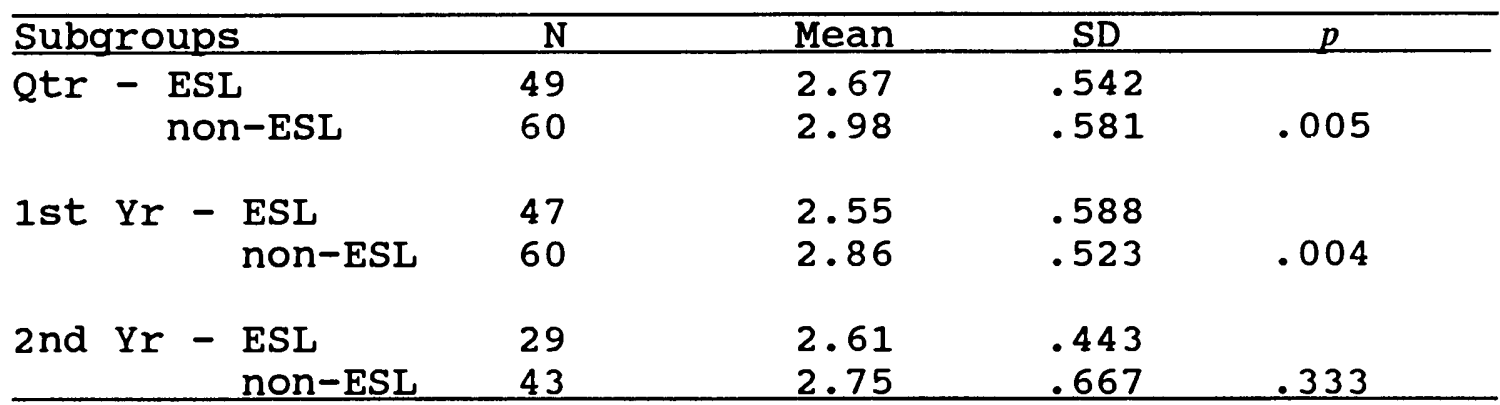

Nationality

While the students from the Middle East in both main groups had nearly identical average GPAs, the standard deviations for the non-ESL subgroup was considerably larger than those for the ESL subgroup. See Table XXI.

TABLE XXI

MEAN ACADEMIC GPA STANDARD DEVIATIONS FOR ESL AND NON-ESL STUDENTS FROM MIDDLE EAST

\begin{tabular}{lccc}
\hline Subgroup & Qtr & 1st Yr & 2nd Yr \\
ESL & .530 & .401 & .389 \\
non-ESL & .660 & .598 & .616 \\
\hline
\end{tabular}


The Asian students' grades demonstrated nearly the same pattern as did the male students. While the ESL subgroup maintained a similar GPA across the two-year period, the non-ESL subgroups' dropped, and the statistical significance of the GPA differences decreased with each measurement. The relationships are shown in Table XXI.

\section{TABLE XXII}

MEAN ACADEMIC GPA DIFFERENCES BETWEEN ESL AND NON-ESL STUDENTS FROM ASIA

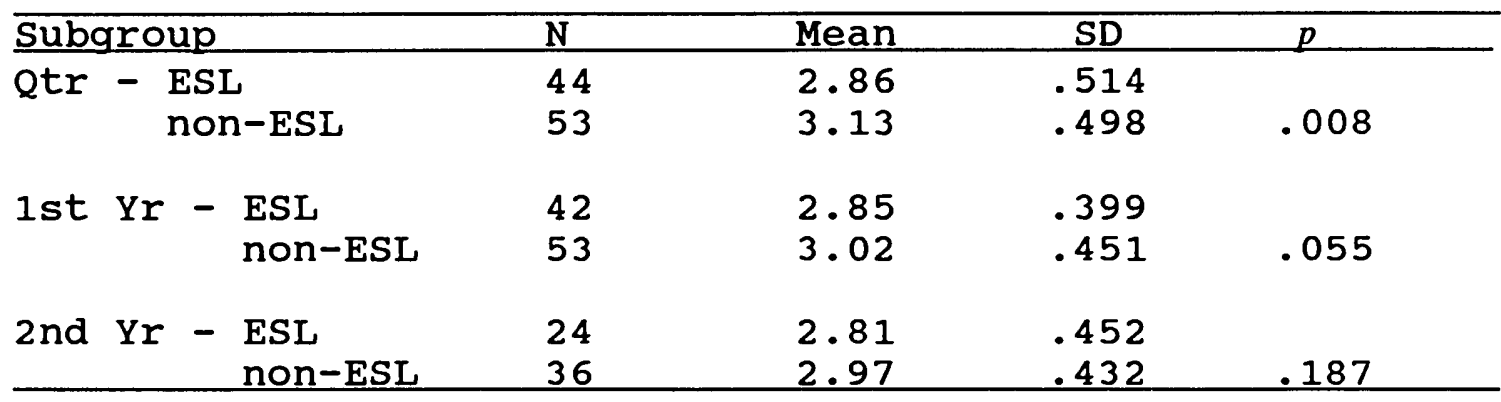

The pattern is similar in all these relationships between ESL and non-ESL students: the former start with lower GPAs than the latter and maintain similar grades across the two-year period, while the non-ESL students' grade averages drop during the same period. This drop and levels of statistical significance for the full group and for the subgroups whose grades also declined are shown in Table XXIII. This finding will be discussed in Chapter V. 
TABLE XXIII

ACADEMIC GPA DROP OF NON-ESL STUDENTS

\begin{tabular}{llccc}
\hline Grouping & N & otr & 2nd Yr & $p$ \\
All & 62 & 3.01 & 2.88 & .19 \\
Male & 42 & 2.99 & 2.81 & $.04 *$ \\
Less-verbal & 34 & 3.00 & 2.84 & .18 \\
Asian & 36 & 3.13 & 2.98 & .09 \\
\hline
\end{tabular}

TOEFL SCORE AND GPA RELATIONSHIPS

\section{TOEFL Score-ESL Grade Correlations}

The Pearson Correlation Coefficients for TOEFL scores and ESL GPAs were statistically significant but not particularly strong. The highest was that with grammar, while the weakest was that with writing. The figures are shown in Table XXIV.

TABLE XXIV

TOEFL SCORE-ESL GPA CORRELATIONS

\begin{tabular}{lcccc}
\hline $\mathrm{N}$ & Grammar & Reading & Writing & Spkg/Lstg \\
\hline $77(59$, gram) & .459 & .370 & .275 & .412 \\
$p=$ & $<.01$ & $<.01$ & .02 & $<.01$ \\
\hline
\end{tabular}

Some interesting contrasts here are that writing grades were those most frequently, strongly, and significantly correlated with academic grades, while reading grades were the least so. The scattergram in Figure 6 illustrates the correlation between ESL grammar GPAs and TOEFL scores. 


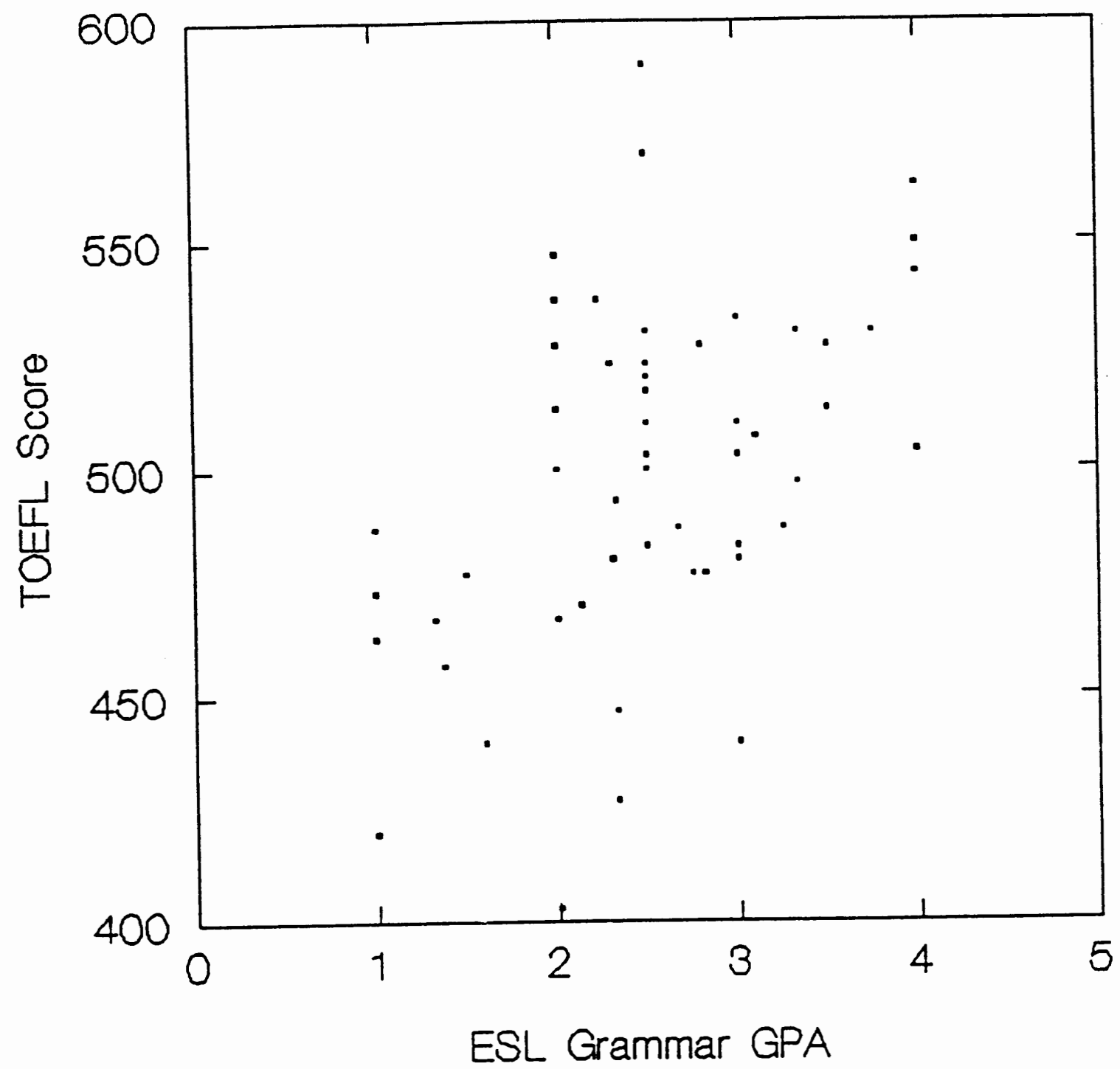

Fiqure 6. Correlation between TOEFL scores and ESL grammar GPAs.

Correlating with Academic Grades

Neither the ESL nor non-ESL students' college grades in this study showed more than weak correlations to their TOEFL scores. For the non-ESL group, in fact, the correlations are near zero, as is shown in Table XXV. 
TABLE XXV

TOEFL SCORE-SECOND YEAR ACADEMIC GPA CORRELATIONS

\begin{tabular}{lccc}
\hline Group & 1st Qtr & 1st Yr & 2nd Yr \\
\hline ESL & .105 & .223 & .086 \\
$p=$ & .38 & .07 & .57 \\
$\mathrm{~N}=$ & 71 & 69 & 42 \\
& & & \\
non-ESL & -.017 & .012 & -.060 \\
$p=$ & .88 & .91 & .66 \\
$\mathrm{~N}=$ & 83 & 83 & 55 \\
\hline
\end{tabular}

Figures 7 and 8 illustrate these relationships.

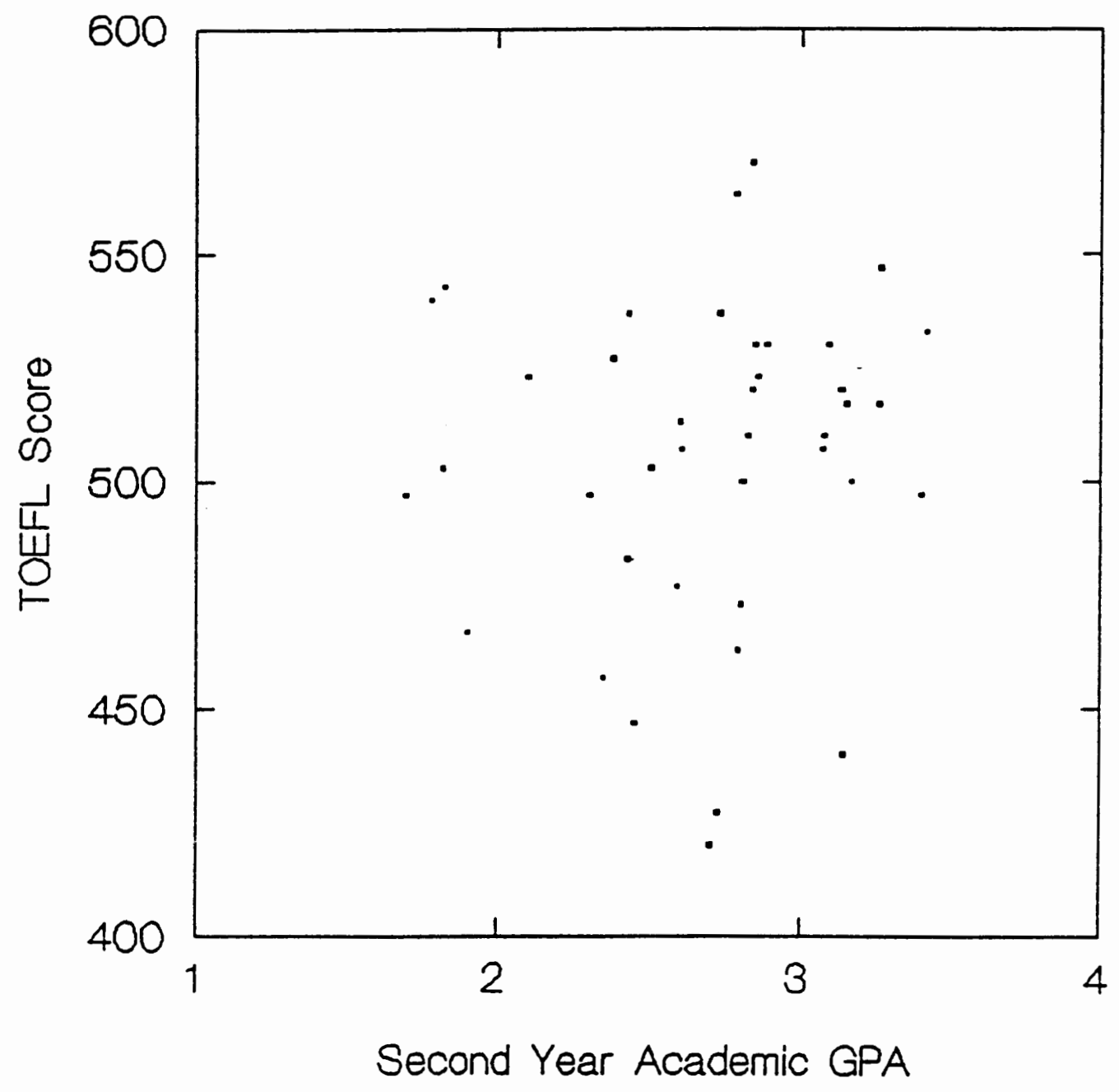

Figure 7. Correlation of TOEFL scores to second year academic grades for ESL students. 


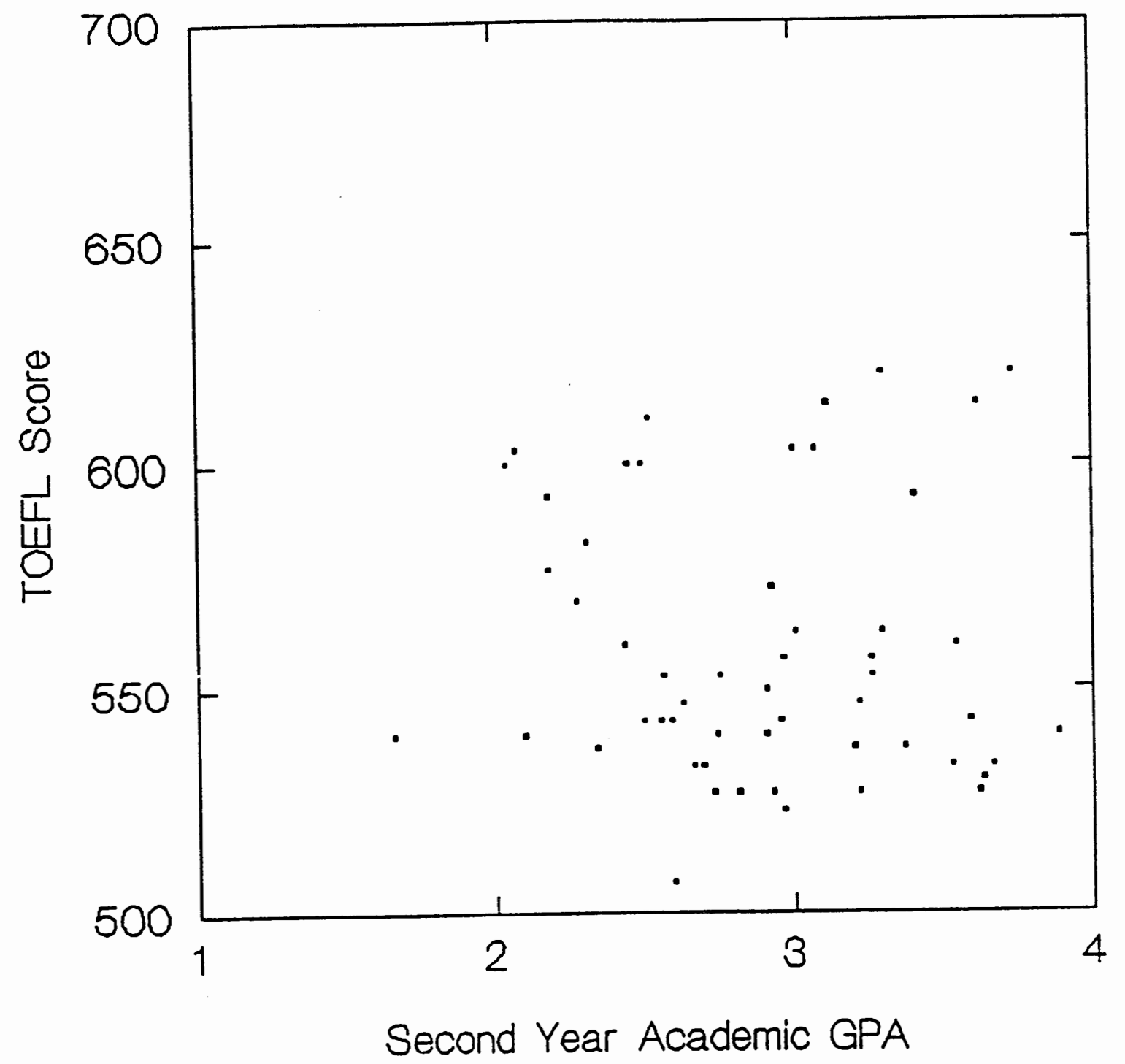

Figure 8. Correlation of TOEFL scores to second year academic grades for non-ESL students. 


\section{CHAPTER V}

\section{DISCUSSION AND IMPLICATIONS}

In Chapter I, I discussed the need for predictors of academic success for international students who come to the U.S. to study. I believe the results of this research show that students' performance in intensive English programs does have predictive validity--more so, perhaps, than do pre-test scores--but must be used cautiously and in combination with other factors. Although the students whose TOEFL scores gained them immediate access to academic study maintained higher grades during the first two years than did their counterparts who had taken ESL classes, that difference narrowed considerably from the first quarter to the second year. As we saw, this equalizing was not due to the ESL students' grades rising, but rather because those who began study without intensive English training started with strong grades and then those grades dropped. These and other factors will be discussed in this chapter.

\section{PREDICTIVE VALIDITY OF ESL GRADES}

As Table I on page 34 shows, there were several statistically significant correlations between ESL grades and academic grades. The problem I see with those 
relationships, though, is that none of the correlations are particularly strong for the whole group and for all the components of ESL. I think there are several possible explanations for this phenomena.

\section{The Perceived Goals of ESL Instruction}

There are perhaps mixed teaching targets among ESL teachers and TAs in the PSU setting. For one thing, there is an attempt to help students achieve a TOEFL score that will admit them to academic study, and the correlations between TOEFL scores and ESL grades suggest that this target is at least partially met. Longitudinally, ESI, students' average scores on both the Michigan and TOEFL do improve as they advance from one program level to the next, as well.

The second perceived goal of the ESL program is to prepare students culturally for an extended stay in the U.S. and for the academic environment here. Many of the texts and activities, especially in the lower levels are directed toward this objective. For example, Asian students, who are known for passivity in the classroom, are drilled on the necessity to become involved, not only in the classroom, but to take some responsibility for their own learning. Many activities such as group work in class and oral presentations backed by research and using audio/visuals force them to adjust at least somewhat to 
this norm. Male students from countries of the Middle East, on the other hand, are usually gregarious and do participate extensively in class. But it is not uncommon for some of them to think (and act) as though they can change a grade by friendly but unrelenting pressure on an instructor. This can happen but is far less likely and acceptable in American culture than in some others. Much of the content of lower-level ESL classes is heavily oriented toward American cultural information--family life, leisure activities, male-female roles, the educational system, food, religions, holidays, etc. This cultural sensitizing may be one of several factors that helps the ESL students maintain their college grades over time, while students without it seem to have trouble doing so.

A third objective, and one that seems it should be of high priority, is to help the ESL students become proficient not only in general English, but in the academic styles and registers of their reading assignments once they enter regular content classes. It is in this area where my research results imply a weakness I will discuss in the following section.

Weaknesses in Predictive Value of ESL Grades

Variation in ESL Component correlations. If all the component GPAs had correlated to academic GPAs as well as did writing, the overall ESL grade correlations would have 
been quite strong. The speaking/listening segment correlations, although not as strong as those for writing, correlated more consistently with academic grades than did those for either reading or grammar.

In the lower levels of writing, emphasis is placed on personal and experiential writing, but at upper levels, the students research, write, and revise much as they will in their content courses. Writing in the ESL program here is strongly process oriented. These factors may explain in part the strong relationship between ESL writing and academic GPAs.

The speaking/listening classes is where most of the culture learning takes place. Not only are many texts and classroom activities directed toward this goal (particularly in levels 1-3), but there are activities outside the classroom that provide cultural orientation. In the two upper levels of this component, a strong emphasis is also placed on note-taking skills and practice. Students may actually attend a college lecture class and take notes as well as have guest speakers in their classrooms. They learn how to outline and abbreviate and practice doing so while listening to a variety of language accents or dialects, tape recordings, and live voices. This preparation, which reinforces activities in the writing class by virtue of emphasizing organization and use of schemata to reduce uncertainty, may explain at least 
part of the consistent positive correlations between this component and college grades.

It is difficult to understand the extreme variation in relationships between grammar and academic grades for students from the Middle East, with a negative -.548 correlation, and that of Asian students, with a positive .504 correlation. Perhaps grammar, thought to be the most subconscious part of language learning, is of little benefit when taught explicitly, except as it relates to the TOEFL. It might also be that learning versus teaching styles play a major role: students whose cognitive style is inductive (creating rules and generalizations from specific examples) may not benefit much from a deductive (presenting grammar rules explicitly, then giving examples) teaching style. The reverse, of course, would also be true. And the two senior instructors in PSU's ESL program teach grammar in these opposite styles. Another possible answer may lie in the degree of contrast between the students native language (NL) and English, the target language (TL). Based on research done by oller and Ziahosseiny (1970), the more similar the TL is to the NL, the more difficult it may be to learn--there is not enough contrast. Since English grammar is far more similar to Arabic grammar than it is to grammars of Asian languages, the students from the Middle East may have much more difficulty with grammar learning 
than do Asian students without regard for their academic skills and performance.

The correlations between ESL reading and college grades were consistently lower than were those of any other components. Also, the majority of negative correlations among the subgroups appeared in this component. Although both women students and students who had previous Englishspeaking college experience showed strong, positive correlations here, most groups did not. Since reading is supremely important in most university classes, it seems logical to assume a strong relationship between grades in ESL reading classes and those in later content courses. One explanation may be that reasonably objective grading is difficult in reading classes. This does not seem likely, though, because most of the ESL teachers I know (including me) think that both writing and speaking/listening are more difficult to grade objectively and consistently. (The distribution curve for ESL reading grades was similar to those of the other components as Appendix $($ shows). Average reading grades were slightly lower than for other components, however.

A more probable explanation lies in the nature of reading material selected for ESL students. Until a little more than two years ago, the ESL program at this university was under the auspices of the English Department, and most of the teachers currently in the program obtained their 
M.A. degrees from that department. Because of these influences, the reading materials used by most teachers in the program lean heavily toward the literary rather than the scholastic. I believe literature has a valid place in learning a language; but the dramatic variations in style among literary works, the lack of academic-type registers, and the difference in content between fiction and poetry on the one hand and college textbooks on the other, perhaps contribute to schema and vocabulary weaknesses during the first several quarters of college as well as difficulty in reading academic style and registers. Reading materials other than literature are used--things such as newspaper and newsmagazine articles, articles about local and regional characteristics and history, various types of essays, and readings selected from ESL textbooks, but rarely are they academic both in style and content.

of 169 subjects in this study, only two were majoring in a literary field, while 92 were majoring in less-verbal fields--fields such as engineering and math. Additionally, most of those majoring in more-verbal areas were students in the School of Business. Only a few of these students will be exposed to more than one or two literature courses during their stay here, but all will be required to do substantial amounts of academic and technical reading. My conclusion, then, is that extensive exposure to collegetype writing styles and registers could make the reading 
component grades correlate better with those of later academic study. (Notice the difference between readingsecond year academic GPA correlations for less-verbal majors--negative -.045, and more-verbal majors--positive .437). This is an area where adjunct courses--ESL classes combined with entry-level academic classes--could benefit students at the intermediate and upper levels of the ESL program. Study methods that would enhance students' reading speed, comprehension, academic vocabulary, and understanding of the typical organization of entry-level textbooks could be included, orienting the classes toward English for Specific Purposes--a strong current trend in ESL worldwide.

Overlap of ESL Subgroups. Scanning the Pearson correlations in Chapter IV could lead one to believe that ESL grades are excellent predictors of university success for certain groups of students--women, Asians, those who took twelve or more ESL classes, those who are in moreverbal majors, and students younger than 24 years of age. But a closer look shows the situation to be more complex. The tables in Appendix B show the composition of the subgroups. All but 3 of the 27 women students were Asian, nearly $2 / 3$ of them took twelve or more ESL classes, and $57 \%$ were in more-verbal majors. Conversely, more than half the male students were from the Middle East, about $60 \%$ of them took fewer than twelve ESL classes, and $2 / 3$ were in lessverbal majors. Because of these crossovers it is difficult 
to determine which variable(s) might have had the strongest effects. If, for example, most of the female students were from South America, would they still show strong relationships between ESL and second year GPAs? It seems that without corroborating research that uses students of different nationalities, there is no way to say with reasonable assurance that ESL grades can be used in a general manner to predict academic success for students from certain cultures or genders more than for others. It is reasonable to say, though, that at Portland state University, the ESL grades of Asian female students who take twelve or more ESL classes and are majoring in a moreverbal area have very strong predictive value. It also seems reasonable to conclude that the ESL grades of male students from countries of the Middle East who take between four and twelve ESL classes and major in less-verbal areas have no predictive value at all, at least at this university.

other Factors. While the composition of the subgroups precludes using their ESL-academic grade correlations with certainty as predictors of academic performance, another element adds to that uncertainty. The sample size within each subgroup was adequate, I think, to draw some conclusions from the correlations for the first academic quarter and, in most cases, the first academic year. The problem is that the strongest relationships found were with 
second year grades where the $\mathrm{N}$ ranged from a low of seven to a high of 27 with the majority in the teens. This situation explains why the levels of statistical significance for the strong ESL-second year correlations were not as great as those for some of the weaker ESL-first year correlations.

The uniformity of mean ESL GPAs among subgroups also raises a question. All but five of eighteen were between 2.49 and 2.62. I see two possibilities here: one is that my point assignment to $\mathrm{P}-\mathrm{NP}$ grades (a little more than $1 / 4$ of the total classes) and my GPA computations that included Ds and Fs as well as the higher repeat grades had a leveling effect; another is that ESL grading, at least at this university may suffer from some sort of unconscious uniformity on the part of the ESL teachers (the variation in mean academic GPAs was broader, ranging from 2.53 to 2.92). A look at the distribution graphs in Appendix C, however, seems to defy these explanations.

Finally, the discovery that students who had previously attended English-speaking colleges performed significantly poorer in ESL than did those without that experience makes little sense to me, because I expected that their previous exposure to formal English would help them do better. One explanation might be that because they had previously studied in English, they were upset over being required to take intensive English classes (perceived 
by them as remedial), and therefore did not do as well as the other subgroup.

\section{Mean Academic GPA Differences}

Three of the five student groups that showed the strongest ESL-academic grade relationships--female and Asian students and those who had attended two quarters or more of college prior to arriving at PSU--received college grades that were significantly higher than those of their subgroup counterparts; and students in more-verbal majors, who also had strong ESL-academic grade correlations, earned college grades that were higher than their counterparts in less-verbal majors, although the difference here was not statistically significant. I think these data point to a valid connection between strong ESL-academic grade correlations and superior college performance. At first glance it appears that comparisons between the students' ESL-academic grade correlations and their mean academic GPAs is somehow inconsistent. The groups with lower ESLacademic grade correlations maintained mean academic grades that were very close to their mean ESL grades, indicating a strong rather than a weak correlation; but the subgroups with strong ESL-academic correlations had mean academic grades that were higher than their mean ESL grades. For example, the group means for both female and Asian students jumped .31 or more from ESL to the first academic quarter. Yet 
those for male and Middle-Eastern students remained quite uniform. The group means are shown in Table XXVII.

\section{TABLE XXVI}

ESL AND ACADEMIC SUBGROUP MEANS BY GENDER \& NATIONALITY

\begin{tabular}{llccc}
\hline Subgroup & ESL & 1st Qtr & 1st Yr & 2nd Yr \\
Female & 2.58 & 2.89 & 2.92 & 2.90 \\
Male & 2.57 & 2.63 & 2.55 & 2.61 \\
& & & & \\
Asian & 2.52 & 2.86 & 2.85 & 2.81 \\
Mid-Eastern & 2.54 & 2.62 & 2.55 & 2.58 \\
\hline
\end{tabular}

A look at the scattergrams for males and females on pages 37 and 38, however, shows the reasons for this phenomenon. As a whole, the males tended to do better in ESL than in academic courses, but there were a scattered few who had very high ESL grades with average or worse college grades and others with rather low ESL grades who did quite well in content studies. The female students' grades on the other hand show a more typical positive correlational sweep from the lower left corner to the upper right corner of the graph.

\section{COMPARING ESL AND NON-ESL STUDENTS}

Although non-ESL students' average grades are still slightly higher at the end of the second year than are those of ESL students, the gap has narrowed substantially. And if we compare the average non-ESL second year grades to those of the ESL students who scored 500 or more on the 
TOEFL, there is essentially no difference at all--2.82 $(\mathrm{SD}=.612)$ and $2.76(\mathrm{SD}=.439)$, respectively. This pattern, much the same as that within the ESL group between students who took fewer than twelve and those who took twelve or more ESL classes, may imply some relationship between intensive English study and the long term academic success of students. It would be interesting to look at mean GPAs for the main groups at the end of the third and even the fourth year. How would they compare at those times?

The findings here were not what I expected. I assumed that ESL students college grades would start lower and climb as they became more English-proficient. Grades of non-ESL students, on the other hand, I expected to start higher and stay there. The patterns I found raise a question of cultural and academic adjustment, including study and note-taking skills; and those are perhaps the areas in which an ESL program is best able to assist its students.

TOEFL SCORES AS PREDICTOR

I performed Pearson Correlation Coefficients between TOEFL scores and GPAs, and although I did not predict results for those tests, the findings did not surprise me. 
TOEFL-ESL Grades

The research I reviewed that had investigated this relationship indicated moderate to strong and statistically significant correlations between these numbers. Because one of the goals of the ESL program at Portland state is to assist students in obtaining a TOEFL score high enough to gain them admission, I expected at least a moderate relationship between TOEFL scores and ESL grades, and I believe the results show that. The Test of Written English (TWE, a writing test created for use with the TOEFL) is usually not given to students entering this university, and therefore, the correlation between ESL writing grades and TOEFL scores is rather weak, though statistically significant. Grammar proficiency figures heavily in the TOEFL, as do listening skills; and the correlation with grammar was the strongest of the four relationships, while speaking/listening was only slightly less so. Although the TOEFL does not test speaking production, it does test listening comprehension, and that element is a big part of the speaking/listening classes. It appears that this goal of the ESL program is being met, at least to some extent.

\section{TOEFL-Academic Grades}

Because most of the studies I reviewed that looked at TOEFL score-college GPA relationships found mostly small to moderate positive correlations, a few of which were 
statistically significant, I expected similar results. None of the other researchers, however, separated ESL from non-ESL students to see if there were differences between correlations for those groups. The two extremely small negative and one extremely small positive correlation for the non-ESL students essentially shows no relationship whatsoever; yet these tests are required by most American universities to determine whether an international student whose first language is not English must enter the intensive English program or is permitted to begin academic study immediately. In at least some cases this is so even if that student comes from a country where English is an official language ( e.g., India, Nigeria, Singapore, Indonesia) and the student has used English from childhood. In contrast to the TOEFL score-academic grade correlations of non-ESL students, those for the ESL students were all positive (although weak) and one--that for the first year academic GPA--was statistically significant. It is not possible to draw any solid conclusions from this difference, but it may again suggest some connection between the type of preparation received in the ESL program and academic performance--the intensive English program goals of helping students improve TOEFL scores, academic performance, and to adjust culturally. The $t$-tests performed on the mean academic grades of the TOEFL score subgroups seems to contradict the results 
of the TOEFL score-academic GPA correlations for ESL students: while the correlations were very low and not statistically significant, the results showed both large and, in two cases out of three, significant differences in academic grades between those students who received a score of less than 500 and those who scored 500 or more on the TOEFL. Since no differences existed between the TOEFL subgroups in the non-ESL groups (divided at a score of 550), the results suggest the possibility that a score of around 500 on the test is a breakpoint below which students generally do not do well academically, but above which (regardless of how far above) they perform better.

Another possibility is that ESL grades and TOEFL scores combined have more predictive value than either does by itself: the ESL grades of students who scored 500 or better on the TOEFL were significantly higher than those of students who scored below 500 .

\section{SUMMARY AND SUGGESTIONS FOR FURTHER RESEARCH}

I believe this research has investigated in greater depth and breadth the relationship between ESL and academic performance than have most others I reviewed, and because of that has suggested some helpful implications for both intensive English programs and university admissions offices. Despite this, there are several problems I see that should be addressed in future studies: a) ESL grades 
need to be compared to grades at or near the end of college study--perhaps at year three or four years or upon graduation (fewer than a dozen of my subjects had graduated, and the total time in academic study for them ranged between 5-7 years) in order to better evaluate the long-term relationship between ESL and academic GPAS; b) comparisons of non-completion rates should be made between ESL and non-ESL students; c) sample or population sizes should be larger and more consistent over time (i.e. from ESL classes through several years of academic study); d) comparison between ESL and non-ESL students need to be made over a longer time period; e) subgroups with more internal variation should be used to better predict which variables truly affect the predictive value of ESL grades; and $f$ ) how learning styles and attitudes toward intensive English study affect the ESL-academic performance correlation.

Relating to the last point, it is quite clear that Asian students, for example, have learning styles different from those of Middle-Eastern or South American students. Attitudes are different as well: in my experience, MiddleEastern students generally protest the most when required to take intensive English classes and complain of little value in them, while Japanese students seem eager to learn English in any way possible. But are these factors related to nationality and culture? or are they more heavily 
related to the perceived value of ESL classes for major fields of study? The majority of Japanese students at PSU major in more-verbal fields while all but one of the Middle-Eastern students in this study majored in lessverbal fields.

It is likely that different intensive English programs vary in their focus, approach, content, and methods. If that is so, a large project across several universities would be desirable to produce information that could be used to make broader generalizations. Such a study would also solve some of the problems listed in the two preceding paragraphs.

It is apparent that TOEFL scores are not good predictors of student academic ability or success, and even the Educational Testing Service (ETS), its creator and administrator, clearly states that. Also, it is a tortuous ordeal for most students who go through it--in many cases, for example, they are not allowed to use a toilet during the several hours of testing. And if they arrive in the U.S. shortly before they take the test, they are likely to be suffering from cultural disorientation. Finally, it gives no information on the cultural preparedness of the students who take it, and perhaps that element is as critical to their educational success in this country as is basic English proficiency. It may, however, have some predictive value when used in conjunction with ESL grades. 
Looking at the results of this research as it applies specifically to this university and its ESL program, it seems that some guarded conclusions can be drawn. The first is that there are variables that influence the relationship of ESL and academic performance as well as academic performance itself. Although it is not clear from this study which of them has or have the most influence, it is probable that the number of ESL classes taken, gender, and nationality are the most important, since subgroups within those categories showed the greatest differences of all the variable groups in their ESL-academic grade correlations; also two of them, gender and nationality, showed the largest subgroup differences among the variables in general academic performance.

The second is that some combination of cultural orientation, study skill training relevant to U.S. university study, and English language proficiency is the best preparation for successful study here. If one looks at the difference in GPA patterns, for example, between the students with the most time spent in the ESL program versus those who have spent little or none, it seems that the program does in some way help students academically. Although most of the non-ESL student declines in mean GPA from the first academic quarter to the second academic year did not show acceptable levels of statistical significance, I believe this pattern has some meaning and value. More 
research similar to this is needed to corroborate the results found here.

A final conclusion is that the reading component of the ESL program does not seem to be preparing students for academic success. It is odd that English reading ability, so crucial in university study, would show such small and irregular correlations with college grades, while grammatical proficiency--something that seems of much less importance, particularly in the sciences--correlated better and more consistently with academic grades for most of the variable subgroups. 


\section{REFERENCES}

Adamson, H.D. (1990). ESL students' use of academic skills in content courses. English for Specific Purposes, $\underline{9}(1), 67-87$.

Apodaca, R. (1985, March). How we educate non-English speaking students successfully. The high intensity language training program description. Paper presented at the annual convention of the National Association of School Boards Association. Anaheim, CA. (ED261532).

Bostic, M. (1981). A correlational study of academic achievement and the Test of English as a Second (sic) Language (TOEFL). Dissertation Abstracts International, $42(2), 468 \mathrm{~A}$. (University Microfilms \#IIA).

Boyer, S.P. \& Sedlacek, W.E. (1988). Noncognitive predictors of academic success for international students: A longitudinal study. Journal of College student Development, 29(3), 218-223.

Brown, J.D. Understanding research in second language learning. GB: Cambridge University Press, 1990.

Burgess, T.C. \& Greis, N.A.F. (1970). English language proficiency among students of English as a Second Lanquage at the college level. Portland, OR: Portland State University. (ED074812).

Case, D.O. \& Richardson, J.V. (1990). Predictors of student performance with emphasis on gender and ethnic determinants. Journal of Education for Library and Information Science, $30(3), 163-182$.

Covert, R. \& Chansky, N. (1975). The moderator effect of undergraduate grade point average on the prediction of success in graduate education. Educational and Psychological Measurement, 35, 947-950.

de Wolf, V.A. (1980). Predictability of first-year University of Washington performance for foreign undergraduates entering autumn, 1978. (Research report \#GAC-80-16). Seattle: University of Washington, Educational Assessment Center. (ED 187270). 
Dunn, I.C.A. (1990). An evaluation of the academic success of students who participated in the English for NonNative Residents program at Portland state University. Unpublished master's thesis, Portland state University, Portland, OR.

English, C.E. (1988). The Test of Written English: A statistical analysis of reliability. Unpublished master's thesis, Portland state University, Portland, OR.

Graham, J.G. (1987). English language proficiency and the prediction of academic success. TESOL Quarterly, $\underline{21}(3), 505-521$.

Gue, L.R. \& Holdaway, E.A. (1973). English proficiency tests as predictors of success in graduate studies in education. Language Learning, 23(1), 89-103.

Harvey, M.J. (1979) - Academic achievement as predicted by the Test of English as a Foreign Language. Unpublished master's thesis, Portland State University, Portland, OR.

Henning, G. A guide to language testing. NY: Newbury House, 1987 .

Hiel, D. \& Aleamoni L. (1974). Assessment of the proficiency in the use and understanding of English by foreign students as measured by the Test of English as a Foreign Lanquage. (Research report \#RR-350) . Urbana: Illinois University, office of Instructional Resources. (ED 093948).

Hosley, D. \& Meredith, K. (1979). Inter- and intra- test correlates of the TOEFL. TESOL Quarterly, 13, 209-217.

Hwang, K. \& Dizney, H. (1970). Predictive validity of the TOEFL for Chinese graduate students at an American university. Educational and Psychological Measurement, 30, 475-477.

Light, R.L., Xu, M. \& Mossop, J. (1987). English proficiency and academic performance of international students. TESOL Quarterly, 21(2), 251-261.

Lindvall, C.M. Measuring pupil achievement and aptitude. New York: Harcourt, Brace \& World, Inc., 1967. 
Lukas, K. (1989). An analysis of the academic performance of international students in the college of Liberal Arts, University of Minnesota, Twin Cities. College and University, $66(1), 19-30$.

Mason, C. (1971). The relevance of intensive training in English as a foreign language for university students. Language Learning, $21(2), 197-204$.

Mossback, G.P. (1977). Service courses in ESL at university level--How effective are they? English Language Teaching, 31(4), 313-318.

Oller, J.W. \& Ziahosseiny, S.M. (1970). The contrastive analysis hypothesis and spelling errors. Language Learning, 20, 183-189.

Perry, W.S. (1989). The relationship of the Test of English as a Foreign Language (TOEFL) and other critical variables to the academic performance of international graduate students. Unpublished doctoral thesis, University of Minnesota, Twin Cities.

Rosberg, W.H. (1983). Students in English as a second language classes: A community college experience. (Research report \#143). Cedar Rapids, Iowa: Kirkwood Community college. (ED234842).

Sharon, A.T. (1972). English proficiency, verbal aptitude, and foreign student success in American graduate school. Educational and Psychological Measurement, 32 , 425-531.

Shilling, K. (1987). Background and treatment variables affecting the academic performance of non-native residents. Unpublished master's thesis, Portland state University, Portland, oR.

Stover, A. (1982). Effects of language admission criteria on academic performance of non-native English-speaking students. Dissertation Abstracts International, 42 (10), 4374A-4375A. (University Microfilms \#IVA).

Sugimoto, R.A. (1966). The relationship of selected predictive variables to foreign student achievement at the University of California, Los Angeles. Doctoral Abstracts, 28(1), 65A.

Wardlow, G. (1989). International students of agriculture in U.S. institutions: Precursors to academic success. Journal of Agricultural Education, 30(1), 17-22. 
White, T.J. \& Sedlacek, W.E. (1986). Noncognitive predictors: Grades and retention of specially-admitted students. Journal of College Admissions, 111, 20-23.

Wilson, R. (1990 November 28) . Foreign students in U.S. reach a record 386,000 . The Chronicle of Higher Education, pp. A1, A36.

Woodbridge, W. (1986). A correlational study of TOEFL scores, intensive English course grades and later academic grade point average at Lewis and clark College. Unpublished master's thesis, Portland state University, Portland, OR.

Zirpoli, T.J., Hallahan, D.P. \& Kneedler, R.D. (1988). The Indonesian Project: Correlates of student performance in a special education teacher training program.

International Journal of Special Education, $\underline{3}(1), 73-79$. 
APPENDIX A

MAIN GROUP COMPOSITION 
APPENDIX A

MAIN GROUP COMPOSITION

COMPOSITION OF MORE-VERBAL AND LESS-VERBAL MAJOR AREAS

Major

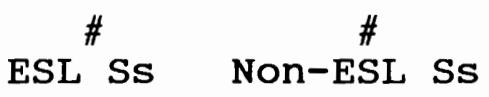

M Accounting (w/more-verbal minor)*

0 Arts \& Letters 0

$\mathrm{R} \quad$ Business Administration

E Business Info Systems

Economics

$\mathrm{V}$ Finance Law

E General Studies

R International Studies

B Marketing

A Political science

L Psychology

Sociology

Theater

$\begin{array}{ll}1 & 4 \\ 0 & 1 \\ 14 & 9 \\ 1 & 4 \\ 7 & 7 \\ 2 & 6 \\ 4 & 1 \\ 1 & 3 \\ 1 & 4 \\ 0 & 1 \\ 2 & 2 \\ 1 & 0 \\ 1 & 0\end{array}$

L Accounting (w/less-verbal minor)*

E Pre-Architecture

$S$ Art

S Biology

Civil Engineering

$\mathrm{V}$ Computer Engineering

E Computer Science

R Electrical Engineering

B Math

A Music

L Mechanical Engineering

Pre-Medicine

Pre-Pharmacy

Physical Education

Science (general)

$\begin{array}{ll}3 & 4 \\ 0 & 1 \\ 2 & 4 \\ 2 & 2 \\ 2 & 4 \\ 2 & 4 \\ 8 & 10 \\ 8 & 13 \\ 3 & 1 \\ 1 & 2 \\ 4 & 3 \\ 1 & 0 \\ 1 & 0 \\ 1 & 2 \\ 4 & 0\end{array}$

*The first two years of accounting is heavily numbers oriented and would seem to argue for placing it in the less-verbal group. But upper level theory and auditing classes emphasize more decision-making in the real world of the organization, regulations, intra-company communication, and information systems. Therefore, I opted to divide accounting majors based upon their minor fields of study. 
COMPOSITION BY GENDER

\begin{tabular}{ccc} 
& \# ESL Ss & \# Non-ESL Ss \\
\hline Male & 49 & 60 \\
Female & 28 & 32 \\
- & &
\end{tabular}

COMPOSITION BY AGE

\# ESL SS \# Non-ESL SS

\begin{tabular}{lll}
\hline Less than 24 years & 38 & 42 \\
24 and older & 39 & 50 \\
\hline
\end{tabular}

\section{COMPOSITION BY NATIONALITY}

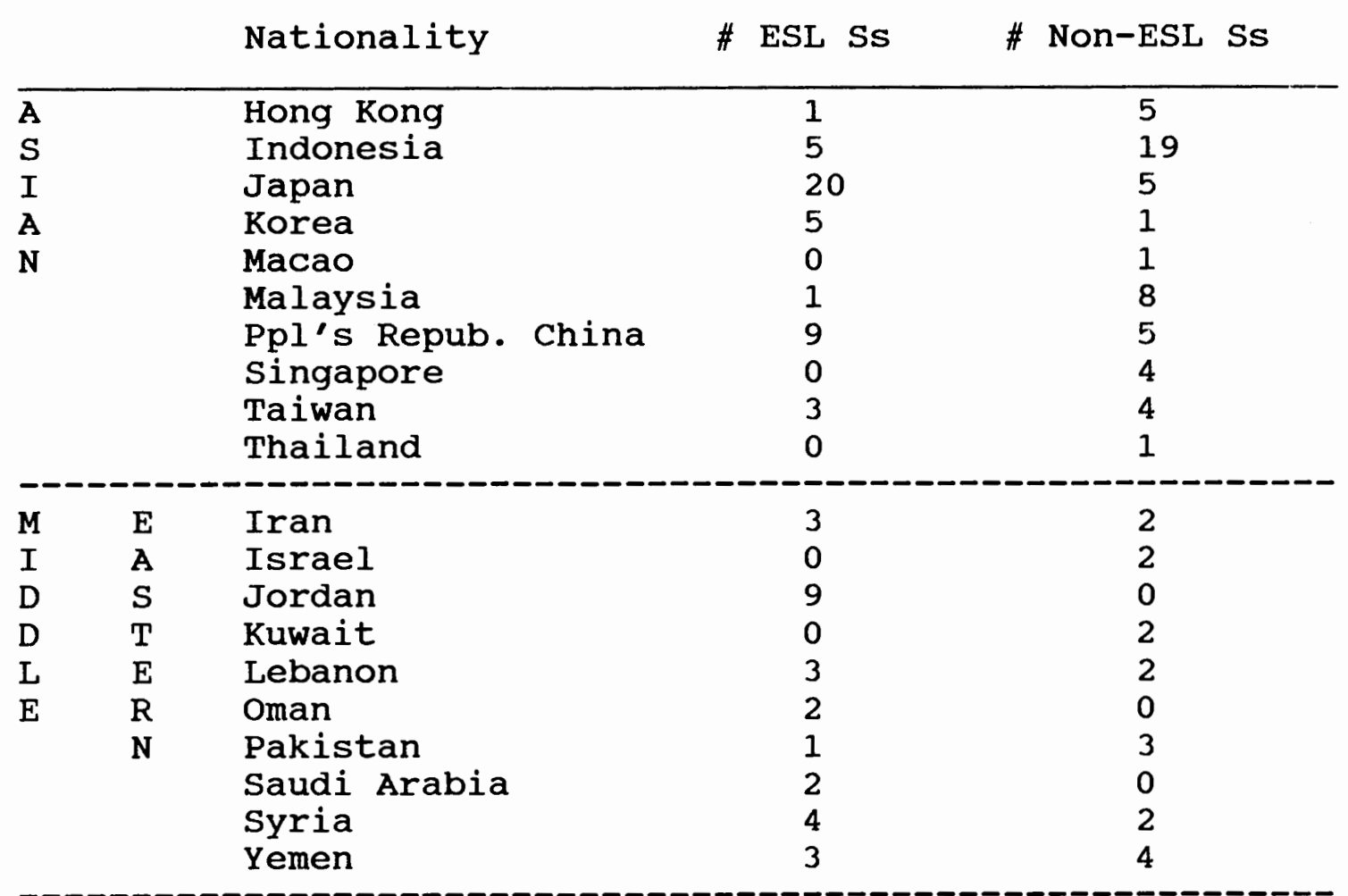


COMPOSITION BY NATIONALITY

(continued)

\begin{tabular}{llll}
$\mathrm{T}$ & Belgium & 0 & 1 \\
$\mathrm{H}$ & France & 0 & 2 \\
$\mathrm{E}$ & Ghana & 0 & 1 \\
$\mathrm{R}$ & Greece & 5 & 2 \\
& Greneda & 0 & 1 \\
& Iceland & 0 & 2 \\
& Italy & 0 & 1 \\
& Kenya & 0 & 1 \\
& Nigeria & 0 & 6 \\
& Norway & 0 & 0 \\
& Senegal & 1 & 1 \\
& Sweden & 0 & 0 \\
& Yugoslavia & 0 & 1 \\
\hline
\end{tabular}

It would require an extremely large sample in order to determine the influence, if any, of specific nationality. Since the primary concern here is the ESL student, and since all but six of those students in this study were either from Asia or the Middle East, this division seemed natural. While there substantial cultural and language differences among the nationalities within the two larger groups, the students within each share more cultural and learning style similarities than they do with those in the other group.

COMPOSITION BY PRIOR EDUCATION LEVEL

Level

\# ESL Ss \# Non-ESL Ss

\begin{tabular}{lll}
\hline HS up to one quarter college & 43 & 29 \\
Two quarters or more & 34 & 63 \\
\hline
\end{tabular}

COMPOSITION BY PREVIOUS ENGLISH-SPEAKING COLLEGE EXPERIENCE

\# ESL SS \# Non-ESL Ss

\begin{tabular}{lll}
\hline Yes & 23 & 32 \\
No & 54 & 60
\end{tabular}

This experience was predominantly at American junior colleges and universities, but about $10 \%$ of the subjects under "yes" had attended colleges 
in Canada, Australia, Great Britain, or other English-speaking countries.

COMPOSITION BY TOEFL SCORES

\# ESL Ss \# Non-ESL Ss

\begin{tabular}{lc}
\hline Less than 500 & 28 \\
500 and up & 43 \\
Less than 551 & 35 \\
551 and up & 48 \\
\hline
\end{tabular}

COMPOSITION BY DATE OF PSU ENTRY

\# ESL SS \# Non-ESL Ss

\begin{tabular}{lcc}
\hline Entered prior to Fall, 1988 & 34 & 19 \\
Entered Fall, 88 or later & 43 & 73 \\
\hline & - & -
\end{tabular}


APPENDIX B

BREAKDOWN BY SUBGROUP 


\section{APPENDIX B}

BREAKDOWN BY SUBGROUP

BREAKDOWN BY NUMBER OF ESL CLASSES TAKEN

$$
\text { 4-11 Classes } 12 \text { and up }
$$

The fewest number of ESL classes taken was 4 ; the most, 33. These include classes at other colleges in the U.S., Canada, Australia, and Great

Britain--66 classes, or $7 \%$ of the total of 994 .

BREAKDOWN BY MAJOR, ESL

\begin{tabular}{|c|c|c|}
\hline Subgroup & ore-verbal & Less-verbal \\
\hline Male & 19 & 30 \\
\hline Female & 16 & 12 \\
\hline Asian & 24 & 20 \\
\hline Mid-Eastern & 10 & 17 \\
\hline$<24$ years old & 24 & 14 \\
\hline 24 and older & 11 & 28 \\
\hline$<12$ ESL Classes & 18 & 20 \\
\hline 12 and more & 17 & 22 \\
\hline Prev Amer College & 10 & 13 \\
\hline None & 25 & 29 \\
\hline
\end{tabular}

BREAKDOWN BY GENDER, ESL

\begin{tabular}{lcc}
\hline Subgroup & Male & Female \\
\hline Asian & 20 & 24 \\
Mid-Eastern & 24 & 3 \\
& & 11 \\
$<24$ years old & 27 & 17 \\
24 and older & 22 & 10 \\
& & 18 \\
12 and more & 28 & 7 \\
Prev Amer college & 16 & 21 \\
None & 33 & \\
- & & \\
-
\end{tabular}


BREAKDOWN BY NATIONALITY, ESL

\begin{tabular}{lcc}
\hline Subgroup & Asian & Mid-Eastern \\
\hline$<24$ years old & 23 & 13 \\
24 and older & 21 & 14 \\
& & 13 \\
$<12$ ESL classes & 19 & 14 \\
12 and more & 25 & 10 \\
Prev Amer college & 12 & 17 \\
None & 32 &
\end{tabular}

BREAKDOWN BY AGE, ESL

\begin{tabular}{lcl}
\hline Subgroup & $<24$ & $24+$ \\
\hline$<12$ ESL classes & 19 & 19 \\
12 and more & 19 & 20 \\
& & 13 \\
Prev Amer college & 10 & 26 \\
None & 28 &
\end{tabular}

BREAKDOWN BY \# ESL CLASSES

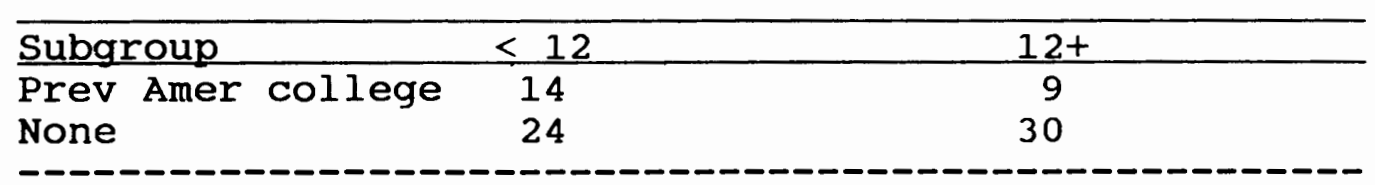

BREAKDOWN BY MAJOR, NON-ESL

\begin{tabular}{lcc}
\hline Subgroup & More-verbal & Less-verbal \\
\hline Male & 20 & 40 \\
Female & 23 & 9 \\
& & 26 \\
Asian & 27 & 15 \\
Mid-Eastern & 1 &
\end{tabular}

BREAKDOWN BY GENDER, NON-ESL

\begin{tabular}{lcc}
\hline Subgroup & Male & Female \\
\hline Asian & 29 & 24 \\
Mid-Eastern & 15 & 1 \\
- & & -
\end{tabular}


APPENDIX C

GPA AND TOEFL SCORE DISTRIBUTION 
94

APPENDIX C

GPA AND TOEFL SCORE DISTRIBUTIONS

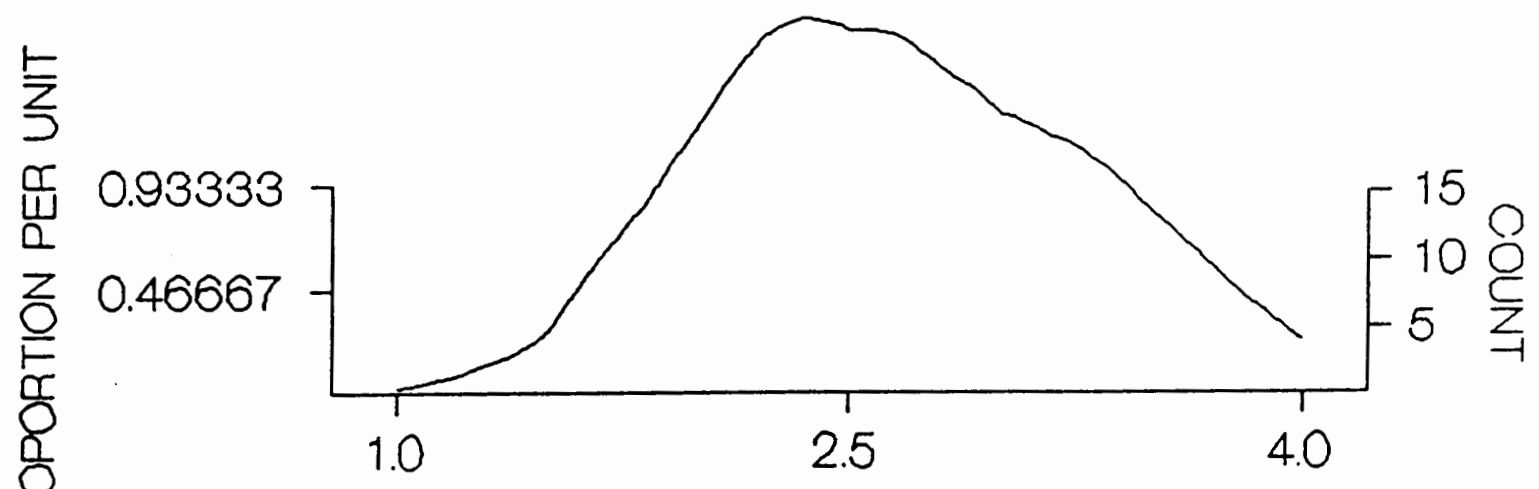

Overall ESL GPA distribution.

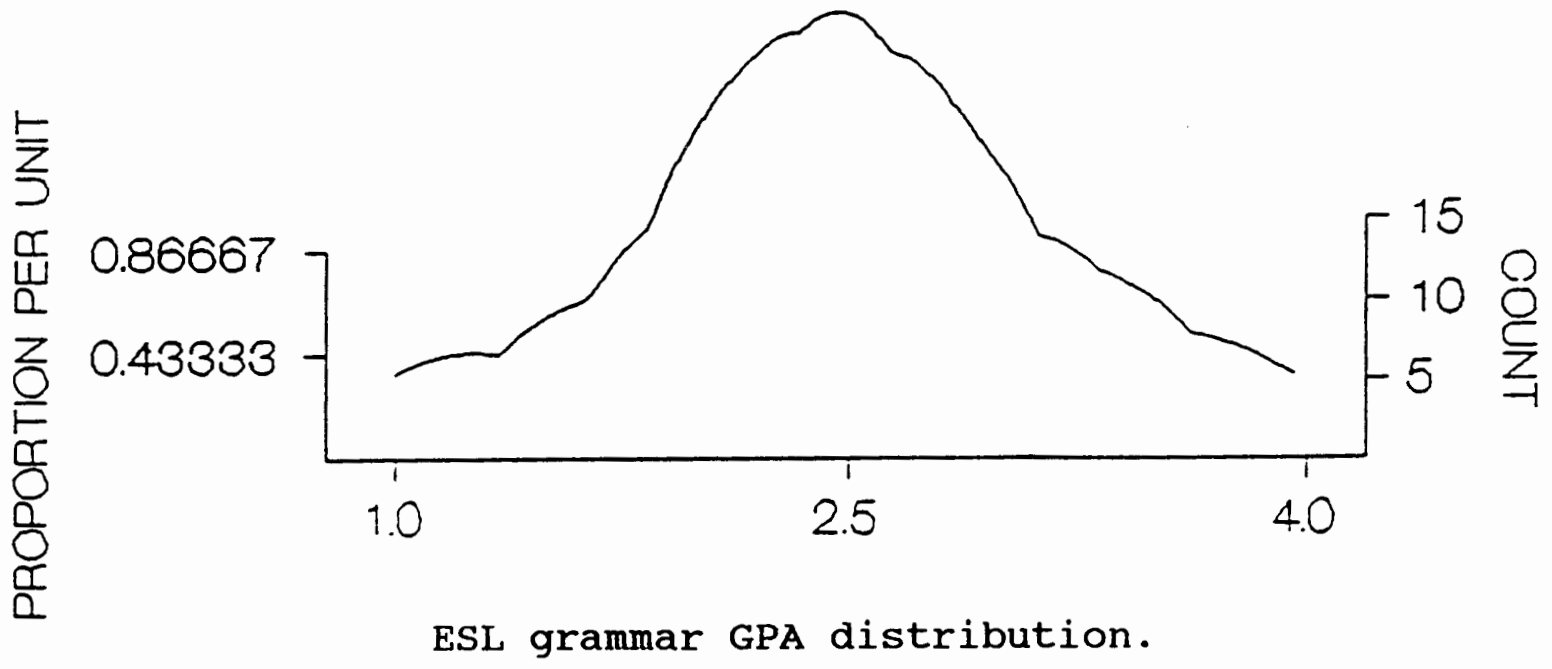




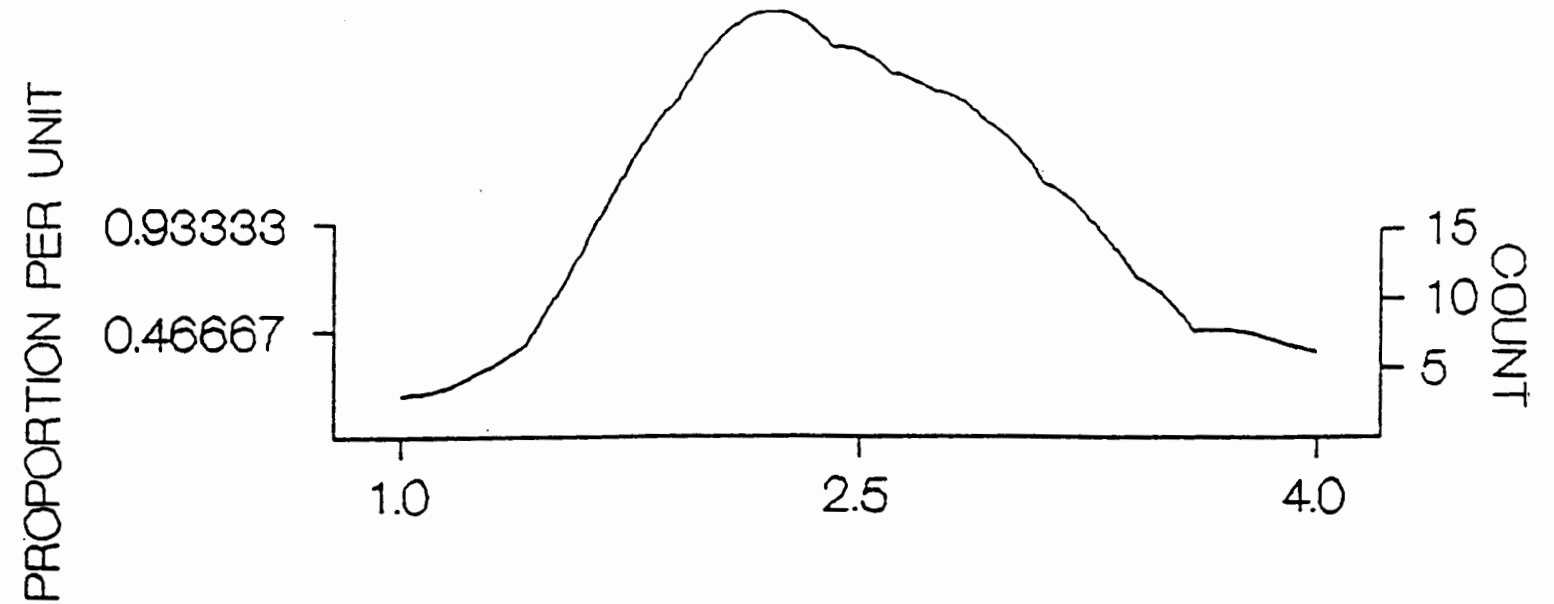

ESL reading GPA distribution.

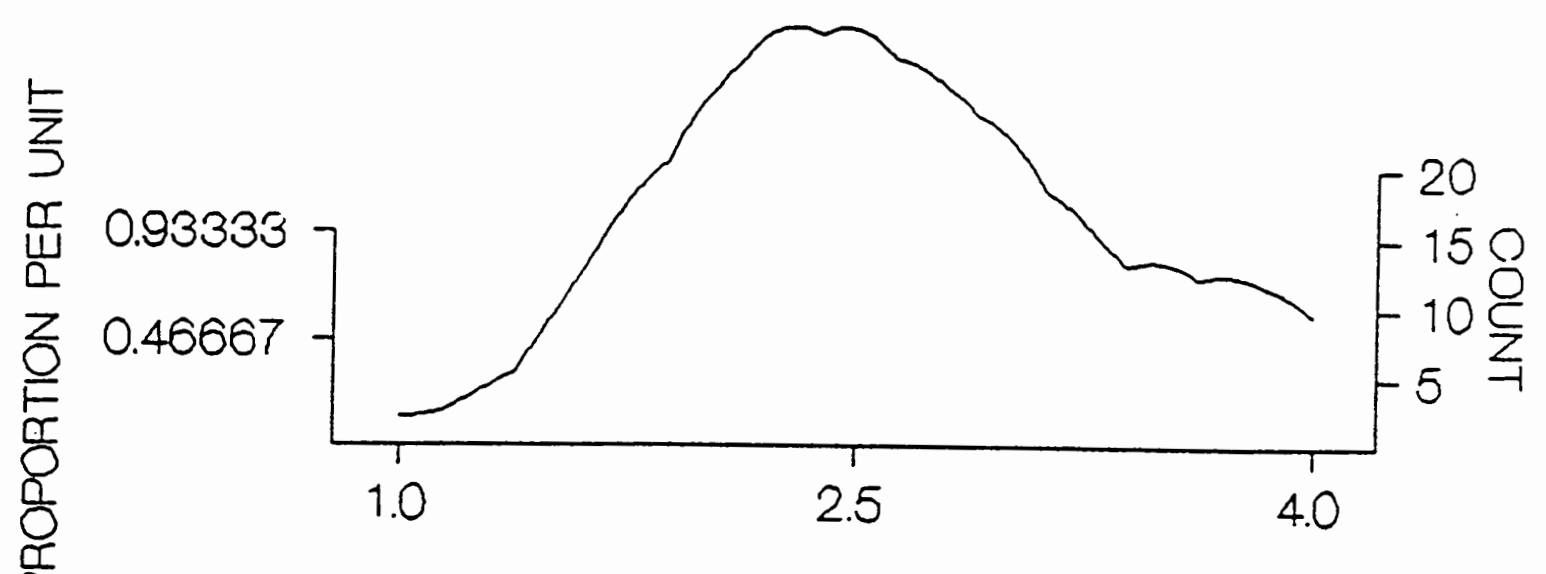

ESL writina GPA distribution.

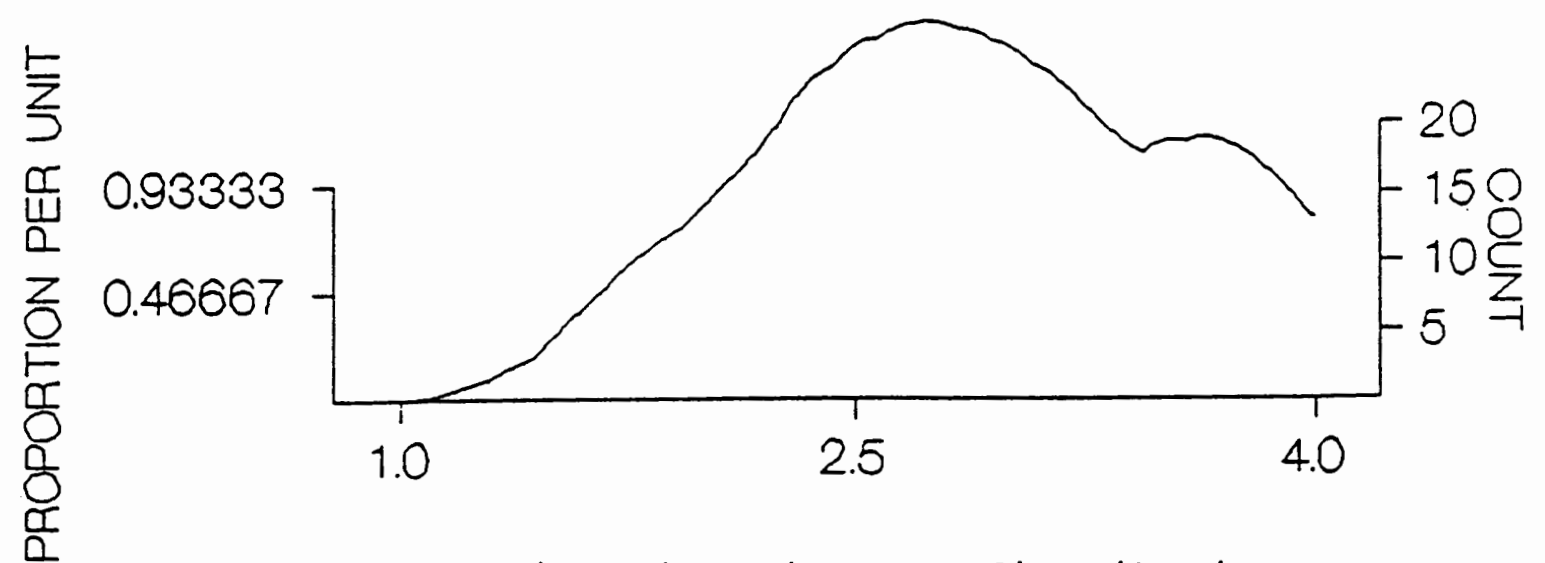
ESL speaking/listening GPA distribution. 


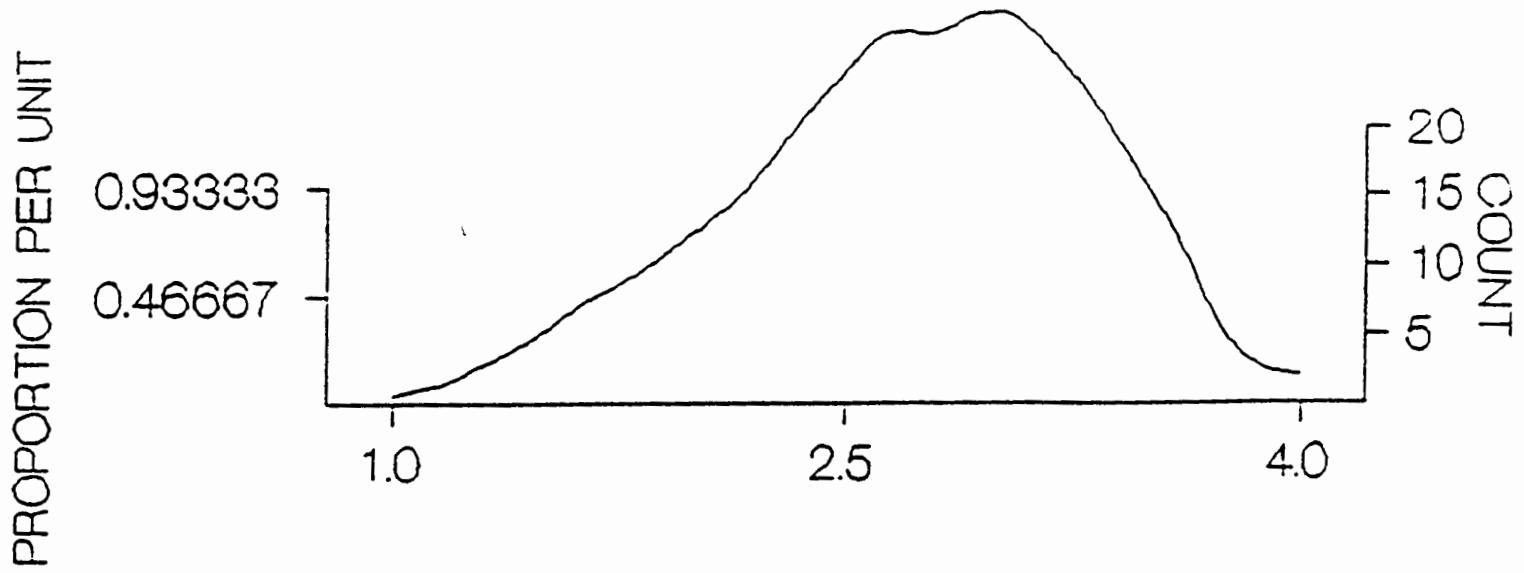

ESL student 1st quarter academic GPA distribution.

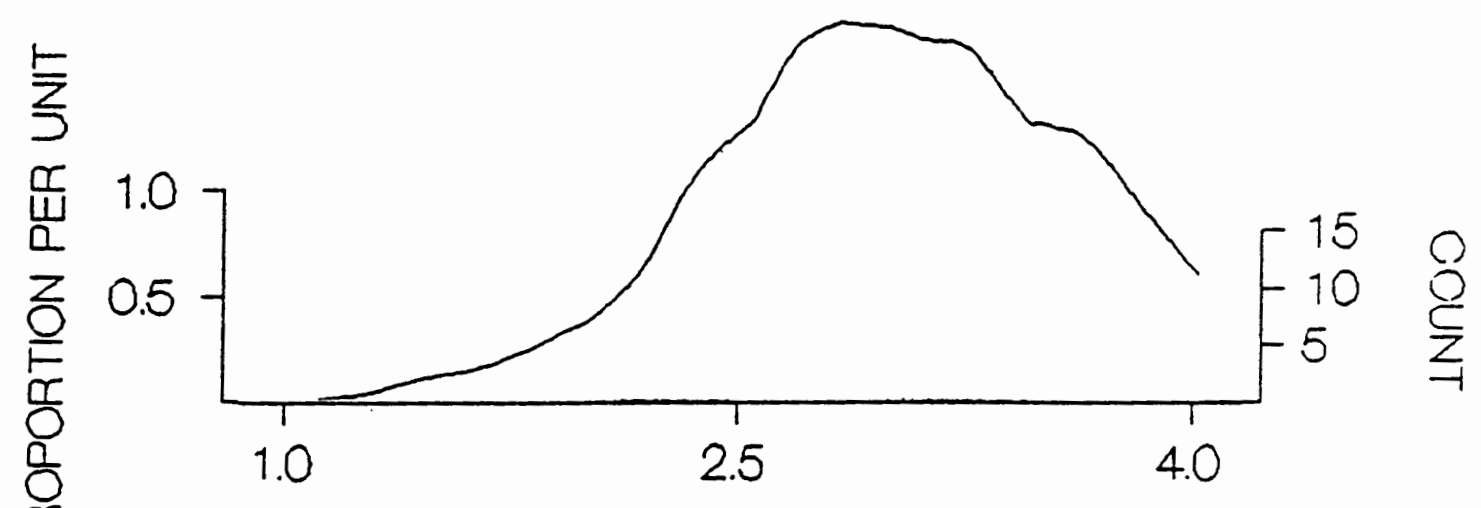

Non-ESL student 1st quarter academic GPA distribution.

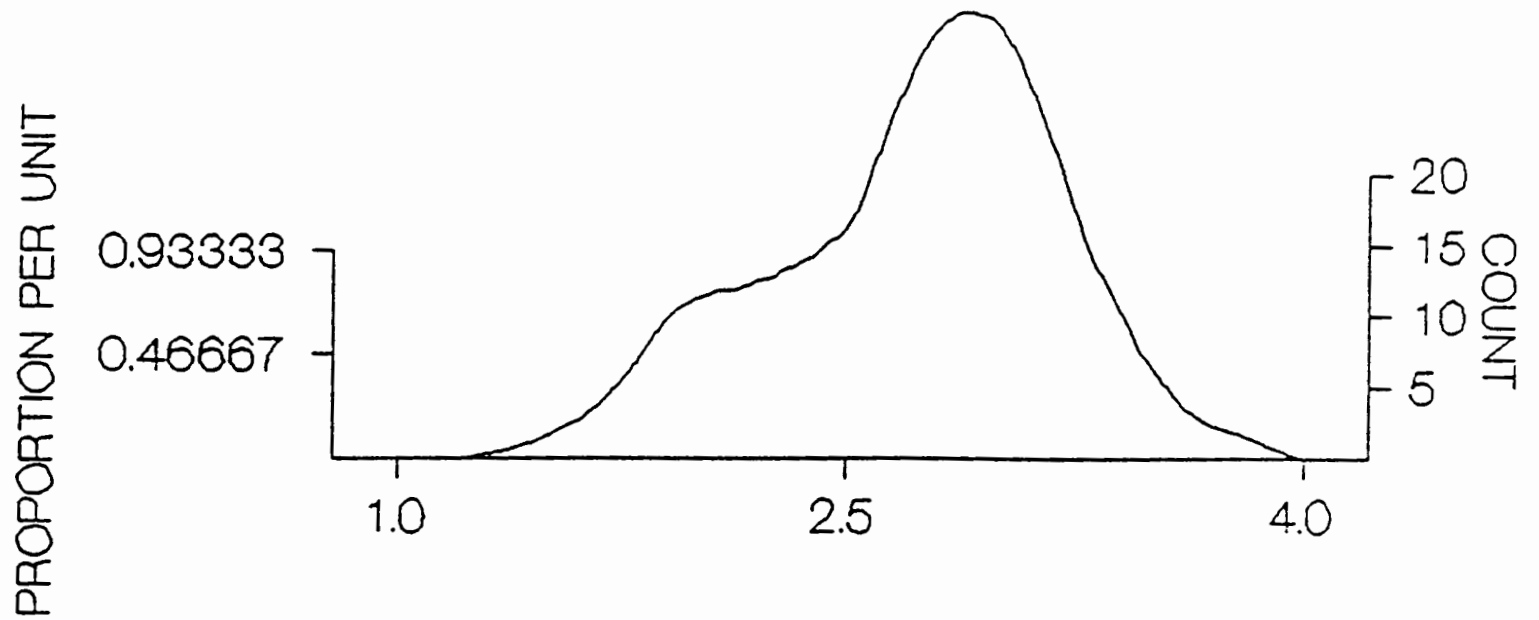

ESL student 1st year academic GPA distribution. 


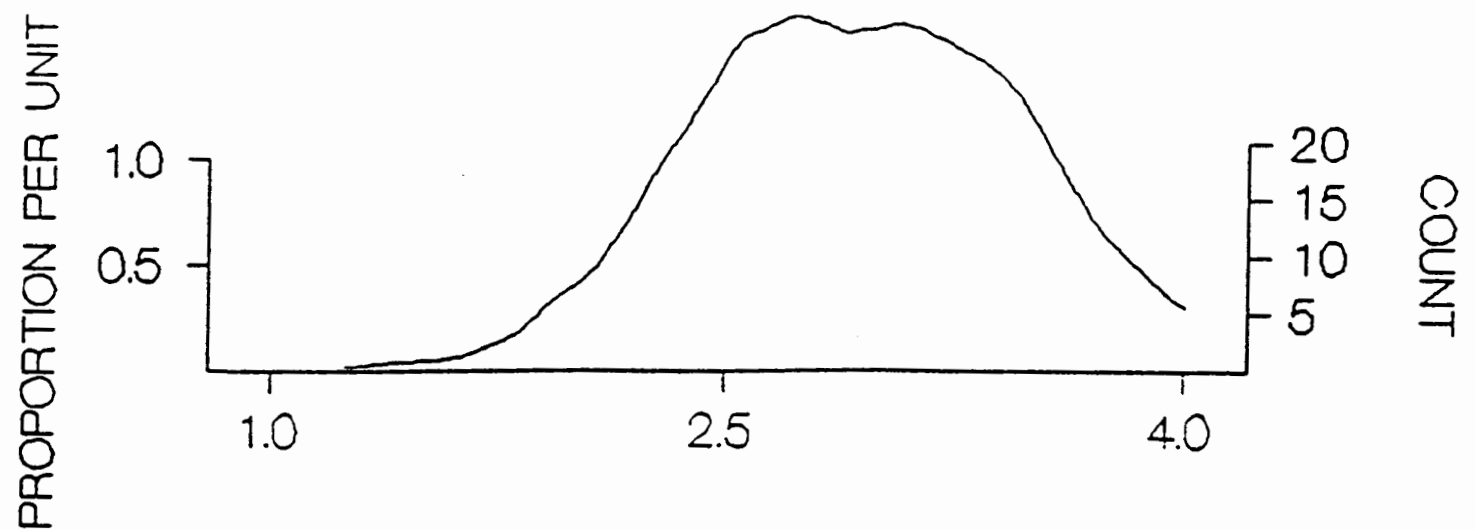

Non-ESL student 1st year academic GPA distribution.

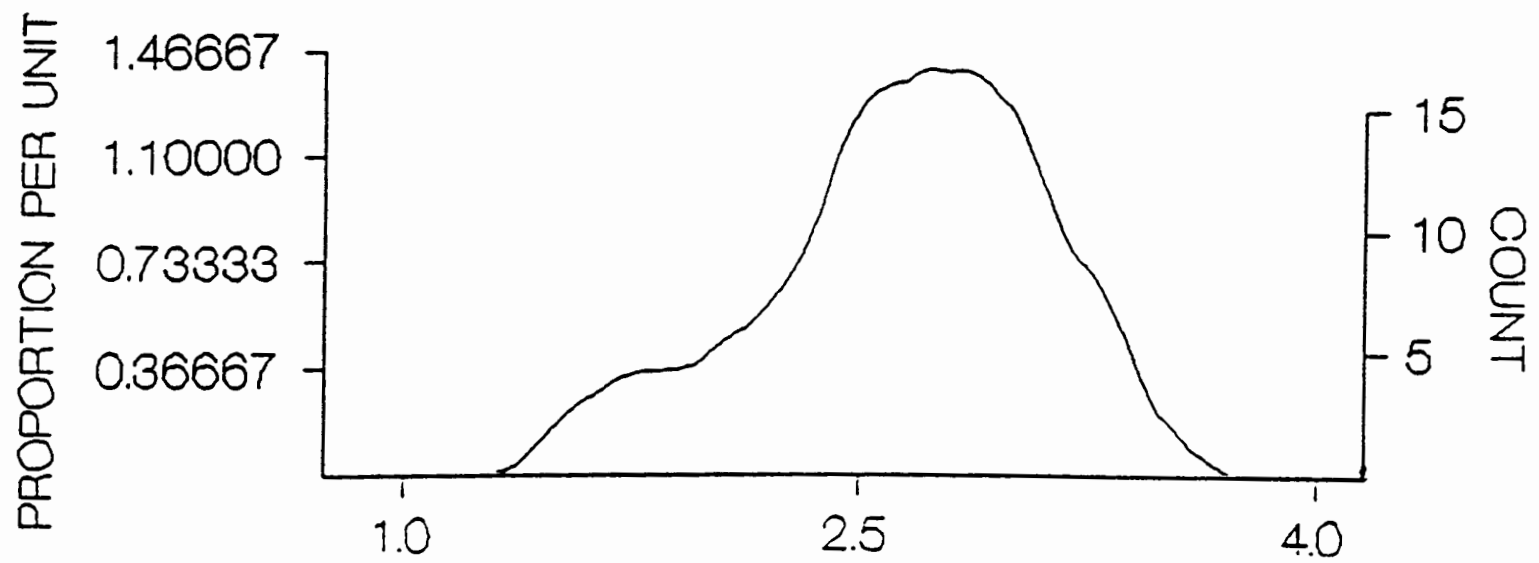

ESL student 2nd year academic GPA distribution.

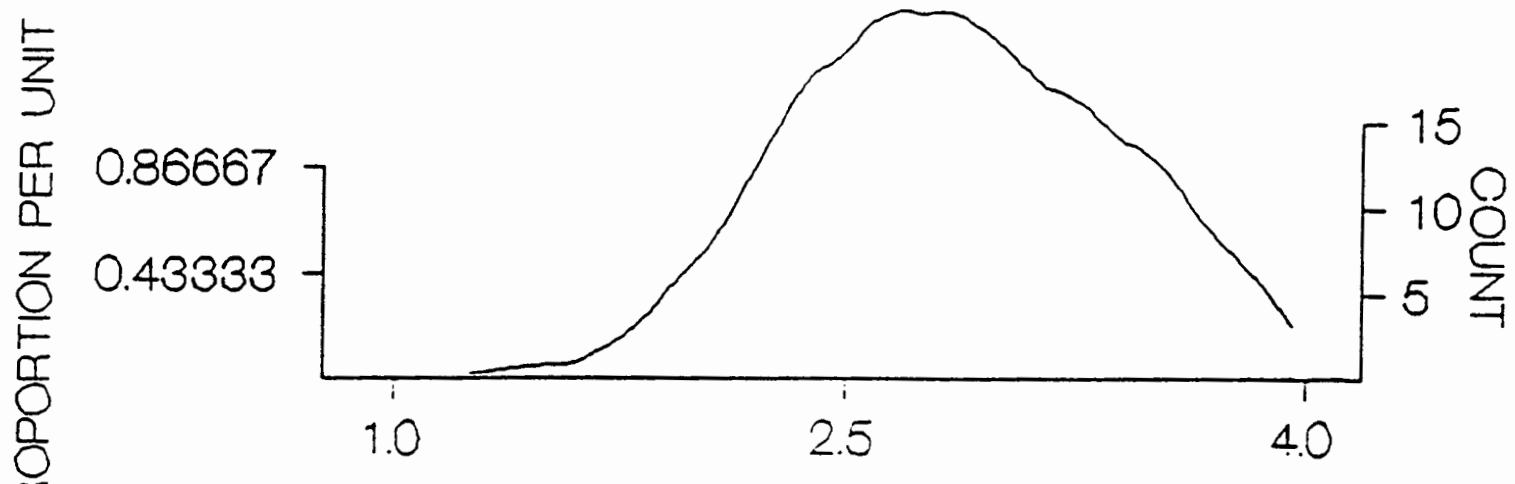

Non-ESL student 2nd year academic GPA distribution. 


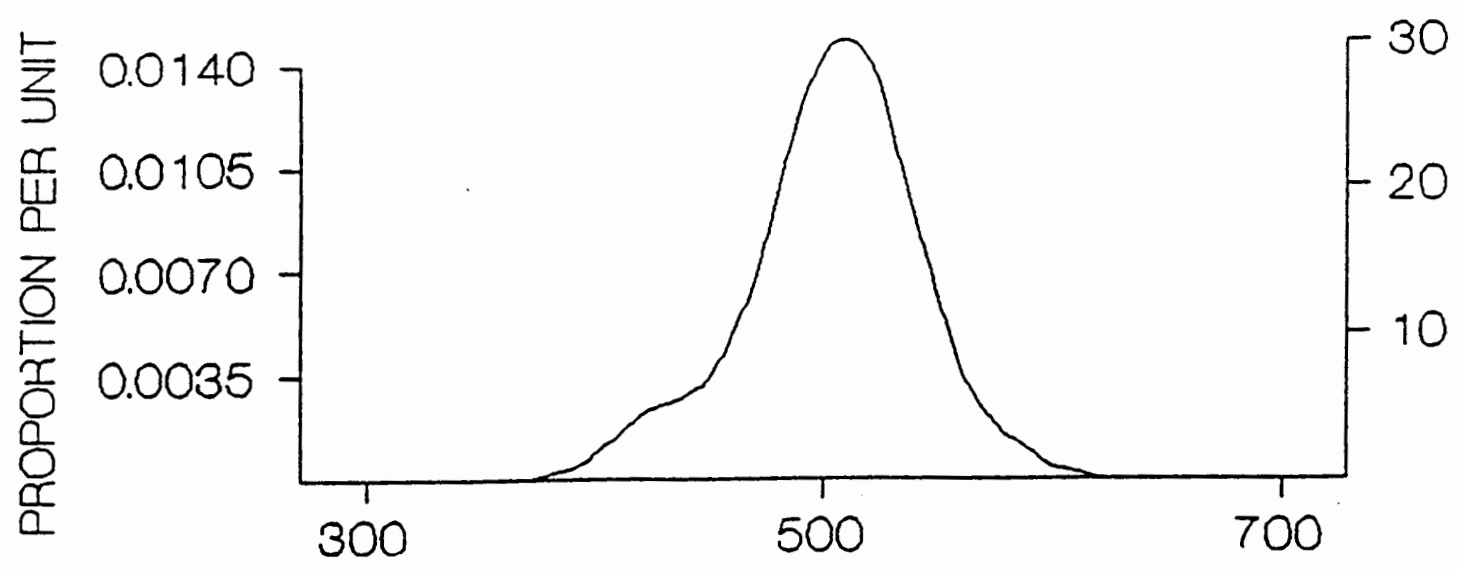

ESL student TOEFL score distribution.

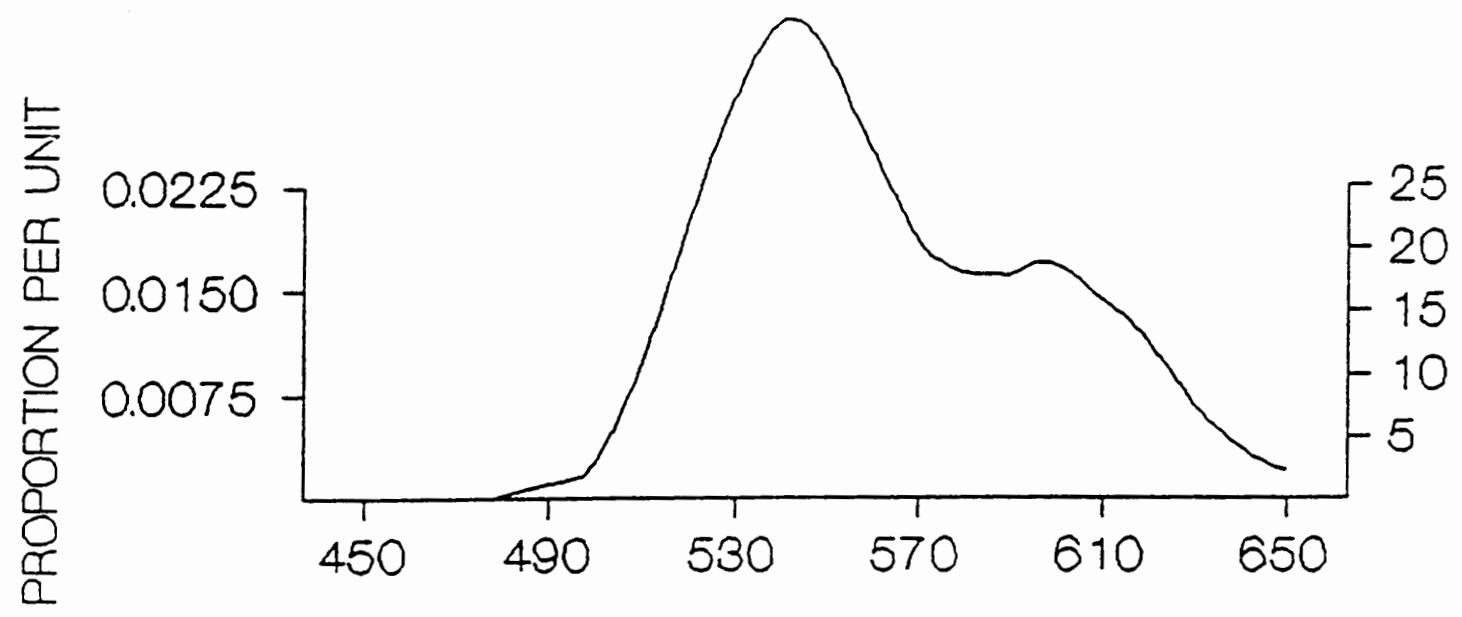
Non-ESL student TOEFL score distribution. 